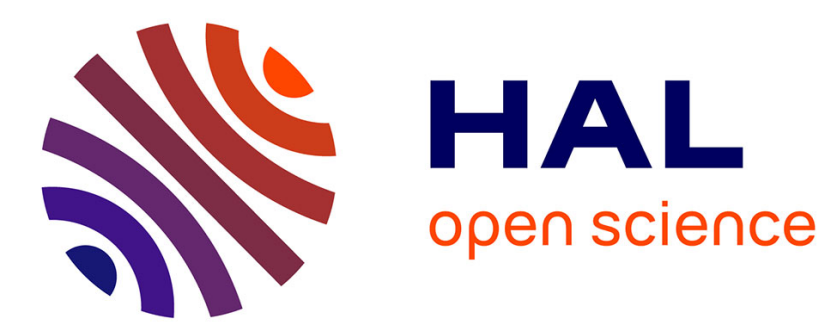

\title{
Les Directives secrètes du Saint Seigneur du Livre de la Grande paix et la préservation de l'unité
}

\author{
Grégoire Espesset
}

\section{To cite this version:}

Grégoire Espesset. Les Directives secrètes du Saint Seigneur du Livre de la Grande paix et la préservation de l'unité. T'oung Pao/ , 2009, 95, pp.1 - 50. 10.1163/008254309x12586659061442 . hal03466464

\section{HAL Id: hal-03466464 \\ https://hal.science/hal-03466464}

Submitted on 20 Dec 2021

HAL is a multi-disciplinary open access archive for the deposit and dissemination of scientific research documents, whether they are published or not. The documents may come from teaching and research institutions in France or abroad, or from public or private research centers.
L'archive ouverte pluridisciplinaire HAL, est destinée au dépôt et à la diffusion de documents scientifiques de niveau recherche, publiés ou non, émanant des établissements d'enseignement et de recherche français ou étrangers, des laboratoires publics ou privés. 


\title{
Les Directives secrètes du Saint Seigneur du Livre de la Grande paix et la préservation de l'unité
}

\author{
Grégoire Espesset* \\ (École Pratique des Hautes Études)
}

\begin{abstract}
This essay provides the first complete study and translation of the Taiping jing shengjun mizhi (HY 1094), a text from the Ming dynasty Taoist Canon. It begins with a discussion of the modern editions and translations of the text, then re-examines the issues of paternity and datation, traces its ideology and textual sources, and finally clarifies its literary structure. The analysis unearths an early textual layer-excerpts of a 2nd- or 3rd-century Taiping jing (Scripture of Great Peace) — and establishes parallels between the received text and several Taoist classics with commentaries through the period of division and up to the Tang dynasty. The text is thus reinstated in the history of Chinese religions throughout the first millennium of our era.
\end{abstract}

\section{Résumé}

Cet article propose la première étude et la première traduction complètes du Taiping jing shengjun mizhi (HY 1094), un texte du canon taoïste des Ming. Il commence par une discussion des éditions et traductions modernes, puis réexamine les problèmes de paternité et de datation du texte, s'interroge sur son idéologie et ses sources textuelles, et finalement éclaire sa structure littéraire. L'analyse met au jour une strate textuelle ancienne - les extraits d'un Taiping jing (Classique de la Grande paix) datant du $\mathrm{II}^{\mathrm{e}}$ ou du $\mathrm{III}^{\mathrm{e}}$ siècle - et établit des parallèles entre le texte reçu et plusieurs classiques taoïstes avec commentaires composés pendant la période de division et jusqu'à l'époque des Tang. Le texte retrouve de la sorte sa place dans l'histoire des religions chinoises pendant le premier millénaire de notre ère.

\section{Keywords}

Daoism, Taiping jing, self-cultivation

\footnotetext{
* Le présent travail a pu être réalisé grâce à un financement de la Nippon gakujutsu shinkōkai 日本学術振興会 (2006-2008).
} 
Abréviations:

DT Daozang tiyao 道藏提要, éd. Ren Jiyu 任繼愈 et Zhong Zhaopeng 鍾肇鵬, $3^{\mathrm{e}}$ éd., Beijing, Zhongguo shehui kexue chubanshe, 2005

TC The Taoist Canon: A Historical Companion to the Daozang, éd. Kristofer Schipper et Franciscus Verellen, Chicago, The University of Chicago Press, 2004

WM Wang Ming 王明 (éd.), Taiping jing hejiao 太平經合校, 1960, $2^{e}$ éd., Beijing, Zhonghua shuju, 1979

Apparu dans la Chine des Han 漢 (de 206 av. n. è. à 220 de n. è.), le thème de l'avènement d'une ère de "Grande paix" (taiping 太平) caractérisée par une adéquation parfaite et pérenne entre l'ordre humain et l'équilibre universel plonge ses racines dans des courants de pensée antérieurs à la fondation de l'Empire ${ }^{1}$. C'est au I $^{\text {er }}$ siècle avant notre ère et au II $^{\text {ème }}$ siècle de notre ère que se seraient produites deux révélations scripturaires distinctes qui, du fait de la dégradation des conditions d'existence des couches sociales les moins favorisées et de la remise en cause de la légitimité de la dynastie régnante, auraient inspiré, sous les règnes des derniers empereurs Han, une organisation communautaire doublée d'une tradition religieuse appelées l'une et l'autre Taiping dao 太本道 (“Voie de la Grande paix")2. La seconde de ces deux révélations, un “écrit divin" (shenshu 神書) intitulé Taiping qingling dao 太平青領 道 (Voie de la conduite pure de la Grande paix), aurait servi de texte de base à ce mouvement socio-religieux ${ }^{3}$. La première révélation, qui

1) Voir Werner Eichhorn, “T'ai-p'ing und T'ai-p'ing-Religion”, Mitteilungen des Instituts für Orientforschung 5, 1 (1957): 113-140; Joseph Needham, "Time and social devolution, ta thung 大通 and thai phing 太平”, in The Grand Titration: Science and Society in East and West, Londres, George Allen \& Unwin, 1969, p. 253-267; Barbara Hendrischke (trad.), The Scripture on Great Peace: The Taiping jing and the Beginnings of Daoism, Berkeley, University of California Press, 2006, p. 4-13.

2) Cette construction téléologique constitue l'histoire reçue que l'on trouve dans la plupart des sources taoïstes et dans une grande partie des publications académiques modernes. Elle pose pourtant de nombreux problèmes, à commencer par celui de l'historicité du rapport entre les deux révélations et le mouvement socio-religieux en question. En outre, l'occurrence de l'expression "Taiping dao" n’a pas la même valeur sémantique selon qu'elle intervient dans une histoire officielle ou dans un texte taoïste. Voir Grégoire Espesset, "Latter Han religious mass movements and the early Daoist church", in Early Chinese Religion. Part One: Shang through Han (1250 BC-220 AD), éd. John Lagerwey et Marc Kalinowski, Leiden, E. J. Brill, 2009, p. 1061-1102.

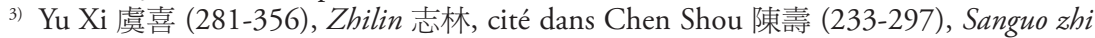
三國志 (297), rééd. Beijing, Zhonghua shuju, 1959, Wu 吳, 46.1110. Ma traduction du titre du livre révélé s'inspire de la leçon "Taiping qingling shu” 太平清領書 donnée par Fan 
concerne un Tianguan li baoyuan taipingjing 天官曆包元太平經 (Livre de la Grande paix garant de la souveraineté [dynastique selon] le calendrier des fonctionnaires célestes), constitue la plus ancienne mention connue d'un document consacré au thème de la Grande paix ${ }^{4}$. Quoi qu'il en soit, aucun de ces deux textes révélés n’a survécu sous ces titres.

Un Taiping jing 太平經 lacunaire (HY 1093, juan 卷 35-119), dont on ignore le rapport historique exact avec les deux écritures révélées et le mouvement socio-religieux de la fin des Han, subsiste dans le Canon taoïste des Ming 明 (1368-1644)5. Ce “texte maître" de la tradition de la Grande paix y est précédé d'une compilation d'extraits, le Taiping jing chao 太平經鈔 (Transcription du Livre de la Grande paix, HY 1093, juan 1-10); il est suivi d'une préface, le Taiping jing fuwen xu 太平經 複文序 (Préface aux caractères redoublés du Livre de la Grande paix) ${ }^{6}$, et du Taiping jing shengjun mizhi 太本經聖君祕旨 (Directives secrètes du Saint Seigneur du Livre de la Grande paix, HY 1094). Avec le manuscrit de Dunhuang 敦煌 “Taiping bu juan di er 太平部卷第二” (Londres, British Library, manuscrit Stein 4226) ${ }^{7}$, ces quatre sources constituent

Ye 范曄 (398-445) dans le Hou Han shu 後漢書 (445), rééd. Beijing, Zhonghua shuju, 1965, 30B.1084, une source plus tardive.

4) Ban Gu 班固 (32-92), Han shu 漢書 (92), rééd. Beijing, Zhonghua shuju, 1962, 75.3192. Ce titre pourrait désigner deux ouvrages, la césure intervenant, selon les éditeurs modernes, après les trois premiers caractères. Un siècle plus tard, Xun Yue 荷悅 (148-209), dans son Han ji 漢紀 (200), rééd. Beijing, Zhonghua shuju, 2002, 28.492, reprend dans un premier temps la leçon du Han shu, puis isole les trois derniers caractères (“Taiping jing”). C'est la plus ancienne occurrence datée du trisyllabe, considéré isolément et sans ambiguïté possible quant à sa lecture.

5) Le Da Ming Daozang jing 大明道藏經 (1444-1445), produit durant l'ère Zhengtong 正 統 (1436-1449), et son supplément le Xu Daozang jing 續道藏經 (1607). Dans la présente étude, les références renvoient à l'édition la plus couramment utilisée du Canon, celle imprimée par la Commercial Press de Shanghai au cours de la décennie 1920, et à ses rééditions. La numérotation des textes, précédée du sigle “HY”, renvoie à Weng Dujian 翁 獨薦 (éd.), Daozang zimu yinde 道藏子目引得, Harvard-Yenching Institute Sinological Index Series n ${ }^{\circ} 25$, Beijing, Yenching University Library, 1935.

6) Cette narration, patchwork de sources historiques et de récits légendaires qui paraît dater du début des Tang 唐 (618-907), constitue l'histoire officielle, réinterprétée par le courant Shangqing 上清 (Pureté suprême), de la tradition de la Grande paix réintégrée dans l'orthodoxie taoïste; voir TC, p. 279-280; DT, p. 520, notice n ${ }^{\circ} 1092$.

7) S.4226 contient la table des matières d'un Taiping jing organisé en 10 parties (bu 部), 170 juan et 366 chapitres, qui refléterait l'état du texte à la fin du vi siècle, après sa réédition par des bibliographes du courant Shangqing. Il est généralement admis que S.4226 renvoie au même Urtext que le Taiping jing canonique et le Taipingjing chao. Reproduction photographique dans Ōfuchi Ninji 大淵忍爾, Tonkō dōkyō: zuroku-hen 敦煌道經—— 圖錄編, Tōkyō, Fukutake shoten, 1979, p. 703-712; étude et traduction dans Grégoire 
le corpus scripturaire actuel de la Grande paix. Tout comme celles des deux œuvres révélées des Han et du mouvement éponyme, l'origine et l'histoire de ce corpus sont mal connues, autant par manque d'information que du fait de la nature mythique et hagiographique des rares témoignages dont on dispose aujourd'hui ${ }^{8}$.

Quatrième et dernier élément de la composante canonique du corpus, les Directives secrètes du Saint Seigneur du Livre de la Grande paix apparaissent de prime abord comme un recueil de versets consacrés à une pratique religieuse appelée "préservation de l'unité", shouyi 守一9. La brièveté de ce recueil, sa forme et son contenu le rapprochent d'autres textes traitant de thèmes analogues, parmi lesquels le Huangtingjing 黃 庭經 (Livre de la Cour jaune), support à la visualisation de l'intérieur du corps humain et de ses divinités, rédigé en vers heptamètres rimés ${ }^{10}$, et le Jinque dijun sanyuan zhenyi jing 金閶帝君三元真一經 (Livre de

Espesset, “Le manuscrit Stein 4226 Taiping bu juan di er 太本部卷第二 dans l'histoire du taoïsme médiéval", in Études de Dunhuang et Turfan, textes réunis par Jean-Pierre Drège avec la collaboration d'Olivier Venture, Genève, Droz, 2007, p. 189-256.

8) Voir Barbara Kandel, Taiping jing. The Origin and Transmission of the "Scripture on General Welfare": The History of an Unofficial Text, Hamburg, Gesellschaft für Natur- und Völkerkunde Ostasiens, 1979; Burchard J. Mansvelt Beck, "The Date of the Taiping Jing", T'oung Pao 66, 4-5 (1980): 149-182; Tang Yijie 湯一介, "Guanyu Taiping jing chengshu wenti” 關於太本經成書問題, Zhongguo wenhua yanjiu jikan 1 (1984): 168-186; Su Baoyang 蘇抱陽, “Taiping jing chengshu de jige wenti” 太平經成書的幾個問題, Shijie zongjiao yanjiu 50, 4 (1992): 14-21; Maeda Shigeki 前田繁樹, Shoki dökyö kyōten no keisei 初期道教經典の形成, Tōkyō, Kyūko shoin, 2004, p. 15-82; Grégoire Espesset, "Editing and Translating the Taiping Jing and the Great Peace Textual Corpus", Zhongguo wenhua yanjiusuo xuebao 48 (2008): 469-486.

9) Ma traduction rejoint celle de Stephen R. Bokenkamp, "Traces of Early Celestial Master Physiological Practice in the Xiang'er Commentary", Taoist Resources 4, 2 (1993): 37-51, qui propose "maintaining unity" (p. 46). Dans le contexte de pratique religieuse dont il est question ici le mot shou désigne avant tout une forme de méditation, mais il a volontairement une valeur polysémique. Henri Maspero, Le Taoïsme et les religions chinoises, Paris, Gallimard, 1971, emploie en alternance "garder l'Un" (p. 313 et 401), qui est la traduction habituelle du syntagme, "se Concentrer sur l'Un" (p. 45), "se concentrer en l'Un" et "concentrer son Un” (p. 398).

10) Le Huangting jing pourrait remonter aux communautés taoïstes religieuses du $\mathrm{II}^{\mathrm{e}}$ siècle de notre ère. Le titre recouvre deux versions, une "ésotérique" (Taishang huangting neijing yujing 太上黃庭内景玉經, HY 331) et une "exotérique" (Taishang huangting waijing yujing 太上黃庭外景玉經, HY 332), dont le rapport diachronique demeure débattu. Voir Kristofer Schipper (éd.), Concordance du Houang-t'ing king: Nei-king et Wai-king, Paris, École française d'Extrême-Orient, 1975, p. 2-11; Mugitani Kunio 麥谷邦夫, “Kötei naikei-kyō shiron” 黄庭内景經試論, Tōyoo bunka 62 (1982): 29-61; Paul W. Kroll, “Body Gods and Inner Vision: The Scripture of the Yellow Court", in Donald S. Lopez, Jr. (éd.), Religions of China in Practice, Princeton, Princeton University Press, 1996, p. 149-155; TC, 
l'unité parfaite des trois principes du Seigneur impérial du Portail d'or, HY 253) du courant Shangqing, consacré à la "préservation des trois unités (ou trinité)" 守三—11.

Le syntagme shouyi, qui désigne l'une des plus anciennes familles aujourd'hui connues de techniques chinoises de méditation et de visualisation, est essentiel à toute tradition spirituelle depuis le début de l'ère impériale ${ }^{12}$. Bien qu'il soit absent du Laozi 老子, l'appareil exégétique qui s'est développé autour de ce texte lui accorde une place centrale, et ce même si son interprétation varie selon les auteurs. Le commentaire que la tradition place sous le patronage de Heshang gong 河上公, et qui date vraisemblablement des Han de l'Est 東漢 (25-220), affirme qu'en préservant l'unité le Saint parvient à l'omniscience et devient un “modèle" (fashi 法式) pour le monde ${ }^{13}$. Dans le commentaire de Xiang'er 想爾, la stricte observance (shou 守) des admonitions de la Voie (daojie 道誡) conditionne la préservation de l'unité; si ces admonitions ne sont pas respectées, l'unité est perdue ${ }^{14}$. Wang Bi 王腼

p. 184-185, notice $n^{\circ} 331$, et p. 96-97, notice $n^{\circ} 332$; DT, p. 149-150, notice $\mathrm{n}^{\circ} 0330$, et p. $150-151$, notice $\mathrm{n}^{\circ} 0331$.

11) On date le Jinque dijun sanyuan zhenyi jing de la période des Six dynasties 六朝 (III ${ }^{\mathrm{e}}-\mathrm{VI}^{\mathrm{e}}$ s.) ou de la dynastie Tang. Poul Andersen, The Method of Holding the Three Ones: A Taoist Manual of Meditation of the Fourth Century A.D., Londres, Curzon Press, 1979, p. 3-11, y voit une des révélations originelles du Shangqing. Ce texte pourrait être une édition séparée d'une partie du Dongzhen taishang suling dongyuan dayou miaojing 洞真太上素靈洞元大 有妙經, HY 1303 (27a-38b), défini comme un assemblage de textes de diverses origines; voir Isabelle Robinet, La révélation du Shangqing dans l'histoire du taoïsme, Paris, École française d'Extrême-Orient, 1984, vol. 2, p. 285-301; TC, p. 595, notice n ${ }^{\circ} 253$, et p. 187 , notice $\mathrm{n}^{\circ} 1314$; DT, p. 110, notice $\mathrm{n}^{\circ} 0252$, et p. 634, notice $\mathrm{n}^{\circ} 1302$.

12) Voir Yoshioka Yoshitoyo 吉岡義豐, Dōkyō to Bukkyō 道教と仏教, vol. 3, Tōkyō, Kokusho kankōkai, 1976, p. 287-314; Isabelle Robinet, Méditation taoïste, Paris, Dervy, 1979, p. 183-201; Kristofer Schipper, Le corps taoïste: Corps physique, corps social, Paris, Fayard, 1982, p. 175-208; Livia Kohn, "Guarding the One: Concentrative Meditation in Taoism", in Taoist Meditation and Longevity Techniques, éd. Livia Kohn et Sakade Yoshinobu 坂出 祥信, Ann Arbor, The University of Michigan Press, 1989, p. 125-158.

13) Daode zhenjing zhu 道德真經詿, HY 682, 2.5a. Pour la date de ce commentaire, voir TC, p. 72, notice $\mathrm{n}^{\circ}$ 682; DT, p. 295-296, notice $\mathrm{n}^{\circ}$ 0677. Traduction dans Eduard Erkes, Ho-shang-kung's Commentary on Lao-tse, Ascona, Artibus Asiae, 1950, p. 164: "If the saint preserves unity, then he knows about all affairs. Therefore he is able to become the empire's model."

14) Laozi daojing, shang, Xiang'er 老子道經上想爾, manuscrit Stein 6825 (fin du ve ou début du $\mathrm{vI}^{\mathrm{e}}$ s.), Londres, British Library, col. 105-106. Pour la date du manuscrit, voir Lionel Giles, Descriptive Catalogue of the Chinese Manuscripts from Tunhuang in the British Museum, Londres, The Trustees of the British Museum, 1957, p. 217, n 6798. Le commentaire de Xiang'er pourrait avoir été composé avant 215; voir Stephen R. Bokenkamp, 
(226-249), pour sa part, emploie shouyi dans son commentaire au passage du Laozi qui explique que le ciel maintient sa pureté (qing 清) en “parvenant à l'unité” (deyi 得一) ${ }^{15}$. Mais à cette époque le syntagme shouyi n'est déjà plus l'apanage du discours taoïste, puisque le lettré Xiang Kai 裏楷 l'emploie en référence explicite à l'abstinence sexuelle du Bouddha dans le mémoire qu'il présenta personnellement au trône en 166 de notre ère ${ }^{16}$.

La mention en tête des Directives secrètes de deux instances divines appartenant au panthéon du courant Shangqing indique que ce recueil ne peut pas être antérieur à la période des Six dynasties et qu'il appartient par conséquent à la phase tardive de l'histoire littéraire de la tradition de la Grande paix. Ce caractère tardif, s'ajoutant à sa brièveté, explique peut-être qu'il soit toujours resté dans l'ombre du texte majeur du corpus. Il y a un siècle, dans son catalogue pionnier du Canon taoïste, le jésuite Léon Wieger (1856-1933) ne faisait que passer sur les Directives secrètes, dans lesquelles il voyait seulement "un discours sur [le Taiping jing]"17. Deux décennies plus tard, les Directives secrètes sont mentionnées par le Japonais Oyanagi Shigeta 小柳司気太 (1870-1940), auteur de la première étude du Taiping jing à l'époque moderne, d'après qui elles ont été ultérieurement annexées au texte maître dans le Canon ${ }^{18}$. Peu après, son compatriote Fukui Kōjun 福井康順 (1898-1991) en attribue

Early Daoist Scriptures, with a contribution by Peter Nickerson, Berkeley, University of California Press, 1997, p. 58-59. Le commentaire pourrait même remonter à une date antérieure, selon Rao Zongyi 饒宗頤, Laozi Xiang'er zhu jiaojian 老子想爾注校茂, Hong Kong, Tong Nam Printers \& Publishers, 1956, p. 87-92; TC, p. 74-77.

15) Daode zhenjing zhu 道德真經註, HY 690, 3.5a. Traduction dans Richard John Lynn, The Classic of the Way and Virtue. A New Translation of the Tao-te Ching of Laozi as Interpreted by Wang Bi, New York, Columbia University Press, 1999, p. 127-128.

16) Hou Han shu, 30B.1082. Rafe de Crespigny, Portents of Protest in the Later Han Dynasty: The Memorials of Hsiang K'ai to Emperor Huan, Canberra, Faculty of Asian Studies in association with Australian National University Press, 1976, p. 30, propose "mental concentration". Sur Xiang Kai, érudit, astrologue, devin et interprète des présages, voir Rafe de Crespigny, A Biographical Dictionary of Later Han to the Three Kingdoms (23-220 $A D)$, Leiden, E. J. Brill, 2007, p. 886-887.

17) Léon Wieger, Taoïsme. Tome I: Bibliographie générale, Hien-hien, Imprimerie de la Mission, 1911, p. 175.

18) Oyanagi Shigeta, “Go Kan jo Jō Kai den no Taihei shöryō-sho ni tsuite" 後漢書襄楷傳 の太平清領書について, in Tōyō-shi ronsō 東洋史論叢, éd. Kuwabara hakushi kanreki kinen kai 桑原博士還暦記念会, Kyōto, Kōbundō, 1930, p. 171. 
la paternité à l'auteur supposé du Taiping jing chao, point sur lequel nous reviendrons ${ }^{19}$.

Dans l'introduction de son édition critique du Taiping jing publiée en 1960, Wang Ming (1911-1992) consacre moins d'une page à décrire les Directives secrètes. Il montre ce que le recueil doit au texte maitre, dresse une synthèse des maigres données historiques disponibles, et finit par rejoindre ses collègues japonais sur le point de son hypothétique paternitén ${ }^{20}$. Cette hypothèse de paternité, que j'appellerai par convention "l'hypothèse sino-japonaise", finit par s'imposer durablement, au point qu'on la retrouve désormais dans toutes les notices consacrées aux Directives secrètes par les catalogues du Canon taoïste. Dans l'actuel catalogue analytique de référence en langue chinoise, par exemple, une page suffit à reprendre les données réunies par Wang Ming et à offrir un aperçu du contenu du recueil basé sur des citations de ses pages 1 et $7^{21}$. La notice de K. Schipper dans le catalogue analytique occidental publié récemment, moins prolixe puisqu'elle ne lui consacre que dix lignes, date notre recueil de la dynastie des Tang, datation non argumentée mais qui dérive certainement de l'hypothèse sino-japonaise. Puis l'auteur constate platement que le "lien direct [du Taiping jing shengjun mizhi] avec le Taiping jing n'est pas clair" et, pour conclure, paraphrase une partie du premier verset ${ }^{22}$.

Si le matériau des Directives secrètes demeure relativement peu exploité, le thème de la préservation de l'unité a davantage retenu l'attention des spécialistes. Oyanagi ("Go Kan jo Jō Kai den no Taihei shōryō-sho ni tsuite", p. 159-162) avait déjà souligné l'importance du thème de l'unité et de sa préservation dans la pensée du Taiping jing. Pour Tang Yongtong 湯用粀 (1893-1964), auteur de l'un des essais les plus polémiques consacrés au Taiping jing, "préserver l'unité" n'est qu'un thème reflétant l'influence du bouddhisme sur ce texte ${ }^{23}$. Yoshioka Yoshitoyo (19161979) invalide cette affirmation, en rappelant notamment que l'idée de

19) Fukui Kōjun, Dōkyō no kisoteki kenkyū 道教の基礎的砰究, $2^{\mathrm{e}}$ éd., Tōkyō, Shoseki bunbutsu ryūtsūkai, 1958, p. 244-250.

20) WM, p. 15-16.

21) DT, p. 520-521, notice $\mathrm{n}^{\circ} 1093$.

22) TC, p. 494-495, notice $n^{\circ} 1102$.

23) Tang Yongtong, “Du Taiping jing shu suo jian” 讀太平經書所見, Guoxue jikan 5, 1 (1935): 7-38 (p. 29-30). L'auteur ne se réfère aux Instructions secrètes qu'une seule fois, p. 37, n. 37. 
préservation de l'unité ontologique ou physiologique se trouve déjà dans le Laozi, dans le Zhuangzi 莊子 et dans le Huainan zi 淮南子 ${ }^{24}$. Enfin, plus récemment, Yamada Toshiaki 山田利明 a montré ce qui distingue la préservation de l'unité de pratiques à première vue analogues qu'expose le Baopu zi neipian 抱朴子內篇 (HY 1177) de Ge Hong 葛 洪 (vers 283-343) ${ }^{25}$, sur lesquelles nous aurons également l'occasion de revenir. Le fait que Yamada et Kamitsuka ne mentionnent pas les Directives secrètes dans leurs travaux peut être interprété comme étant révélateur du peu de considération dont jouit ce texte, $\mathrm{y}$ compris auprès de spécialistes. Aussi ne semble-t-il pas excessif de clore ce survol historiographique en affirmant que l'essentiel reste à faire pour comprendre les Directives secrètes et envisager, par la suite, la possibilité de les situer dans l'histoire du taoïsme.

\section{Éditions}

L'édition canonique originale des Directives secrètes est disponible en deux versions. La première apparât dans le Canon réimprimé à Shanghai au cours des années 1920, puis en Chine continentale et à Taiwan ${ }^{26}$. Bien entendu, elle n'est pas ponctuée. La seconde version est une reproduction de la première à laquelle une ponctuation complète a été ajoutée en surimpression. Cette seconde version a été publiée à la suite du texte maître dans l'un des plus volumineux fascicules de la série commercialisée sous le nom de “Zhuzi baijia congshu” 諸子百 家叢 27 .

Une transcription ponctuée mais partielle avait été préparée par Wang Ming et insérée en annexe à son édition critique, le Taiping jing hejiao.

24) Yoshioka, Dōkyō to Bukkyō, vol. 3, p. 315-351; voir aussi Kamitsuka Yoshiko 神塚淑 子, Rikuchō dōkyō shisō no kenkyū 六朝道教思想の㸴究, Tōkyō, Sōbunsha, 1999, p. 348-353.

25) Yamada Toshiaki, Rikuchō dōkyō girei no kenkyū 六朝道教儀禮の㸴究, Tōkyō, Tōhō shoten, 1999, p. 27-48. Pour la date du Baopu zi neipian, voir TC, p. 70-71, notice $\mathrm{n}^{\circ} 1185$. Ge Hong aurait achevé une première version du Baopu zi en 317 mais n’en aurait définitivement arrêté le texte que vers 330 .

26) Le recueil n'est pas affecté par les divergences — omissions, déplacements et interversions de feuillets - existant entre les éditions chinoises et taïwanaises du Canon et relevées par Judith Magee Boltz, "Notes on modern editions of the Taoist Canon", Bulletin of the School of Oriental and African Studies 56, 1 (1993): 87-95.

27) Taiping jing 太本經, Shanghai, Shanghai guji chubanshe, 1993, p. 572-576. 
La mise en regard de cette première version ponctuée et de l'édition originale montre que la première moitié du premier verset manque, ainsi que 14 versets entiers, répartis en deux groupes (versets 4-6 et 14-24 dans ma traduction). Wang n'a pas oublié ces versets mais les a utilisés ailleurs dans son édition critique pour collationner le Taiping jing et le Taiping jing chao ${ }^{28}$. La ponctuation est fiable, mais la transcription ne respecte pas scrupuleusement la leçon du texte original (le caractère guang 光 est dédoublé, sans justification, dans le verset 8). Or, par suite d'une négligence, c'est cette transcription fragmentaire qui a été incluse dans le monumental Zhonghua daozang 中華道藏 en 48 volumes récemment publié en Chine continentale, qui se veut l'édition critique définitive du corpus des œuvres taoïstes ${ }^{29}$. Le spécialiste chargé du volume consacré aux textes de la Grande paix, Wang Ka, a bien rétabli les 80 caractères correspondant à la première moitié du premier verset, mais il a omis les deux séquences de versets manquants. Le lecteur ignore ainsi qu'il a en réalité sous les yeux une reprise de la transcription d'un texte source réduit de plus de $22 \%$, puisque 398 caractères sur 1771 n'y figurent pas.

L'unique transcription complète existante des 58 versets, peu connue des chercheurs, a été établie pour les besoins d'un ouvrage de vulgarisation destinant au public chinois, sur le modèle des Treize classiques (Shisan jing 十三經) de la tradition lettrée orthodoxe, "treize classiques taoïstes” typographiés en caractères simplifiés et traduits en langue chinoise moderne $\mathrm{e}^{30}$. Le doublement de caractère au verset 8 prouve que la transcription a pris pour modèle celle de Wang Ming, mais les quatorze versets déplacés ont bien été rétablis, contrairement à ce que l'on vient d'observer dans le cas du Zhonghua daozang. L'introduction (p. 1009-1010) répète celle de Wang Ming, l'appareil de notes joint à

28) WM, p. $739-743$ (transcription de 44 versets); p. 16 (passage correspondant aux versets 4 à 6); p. 282-284 (versets 14 à 22); p. 409-410 (verset 23); p. 410 (verset 24). La transcription par Wang Ming des 44 versets figure dans une annexe de son édition critique regroupant toutes les citations du Taiping jing qui ne recoupent pas la version canonique et, de ce fait, n'ont pas pu être localisées dans le corps du texte.

29) Wang Ka 王卡 (éd.), “005-Taiping jing shengjun mizhi”, in Zhonghua daozang, éd. Zhang Jiyu 張繼禹, Beijing, Huaxia chubanshe, 2004, vol. 7, p. 318-320.

30) Wang Juncai 王俊才 (éd.), “Taiping jing shengjun mizhi”, in Wenbai duizhao daojiao shisan jing 文白對照道教十三經, éd. Ning Zhixin 寧志新, Shijiazhuang, Hebei renmin chubanshe, 1994, p. 1010-1020. 
la transcription est minimal (p. 1014), et la traduction est de qualité médiocre.

Bien que la transcription des Directives secrètes qui y figure ne compte que 44 versets (dont un incomplet) sur 58, l'annexe de Wang Ming est devenue habituelle dans les éditions critiques modernes du Taiping jing qui se sont multipliées en Chine depuis le début des années 1990. Comme l'édition des "treize classiques" taoïstes, les plus récentes lui adjoignent une traduction en langue chinoise moderne ${ }^{31}$. Ces traductions, indiscutablement utiles aux lecteurs sinophones non formés à la langue classique, ont en commun la liberté prise avec la source originale pour contourner les difficultés du texte et le choix contestable des composés de la langue moderne supposés rendre des notions visiblement mal comprises.

Pour en finir avec les traductions, il convient de signaler qu'environ un tiers du recueil a été traduit en anglais par Livia Kohn. On peut regretter que le caractère pionnier de cette traduction constitue son principal mérite et qu'elle ne soit pas vraiment représentative du talent de la traductrice, pas plus que le mince appareil introductif qui la précède, dans lequel notre recueil est prudemment défini comme "une brève collection de méthodes de méditation du Taiping jing", sans plus $^{32}$. Il s'agit à ce jour de l'unique traduction du recueil jamais publiée dans une langue occidentale.

31) Il n'existe qu'une transcription en caractères traditionnels, celle de Yu Liming 俞理明 (éd.), Taiping jing zhengdu 太平經正讀, Chengdu, Ba Shu shushe, 2001, p. 560-563. Les transcriptions en caractères simplifiés comprennent: Yang Jilin 楊寄林 (éd.), “Taiping jing shidu” 太平經釋讀, in Zhonghua daoxue tongdian 中華道學通典, éd. Wu Feng 吳楓 et Song Yifu 宋一夫, Haikou, Nanhai chuban gongsi, 1994, p. 635-638; révisée et augmentée d'une traduction en chinois moderne dans Yang Jilin (éd.), Taiping jing jinzhu jinyi 太 本經今注今譯, Shijiazhuang, Hebei renmin chubanshe, 2002, p. 1765-1777; Luo Chi 羅 熾 (éd.), Taiping jing zhuyi 太平經注譯, Chongqing, Xinan shifan daxue, 1996, p. 1250-1252 (transcription seule); Long Hui 龍晦 (éd.), Taiping jing quanyi 太平經全譯, Guiyang, Guizhou renmin chubanshe, 2000, p. 1534-1546 (transcription accompagnée d'une traduction en chinois moderne). Le fait que les mêmes 14 versets sont manquants dans toutes ces transcriptions et traductions prouve qu'elles découlent d'une source commune.

32) Livia Kohn (trad.), The Taoist Experience: An Anthology, New York, State University of New York Press, 1993, p. 193-197. Kohn, "Guarding the One", p. 139, avait précédemment traduit le verset qui porte le ${ }^{\circ} 3$ dans ma traduction. 


\section{Analyse du titre et du sous-titre}

Il faut souligner d'emblée que la préservation de l'unité est absente du titre, bien que ce soit le thème central du recueil et un énoncé récurrent de son discours. Ce titre se compose de trois éléments: (1) une mention du texte source ("Taiping jing"); (2) l'appellation d'un personnage (Shengjun 聖君); (3) le syntagme mizhi 祕旨 (“directives secrètes”). Dans le Canon taoïste ce syntagme désigne les matériaux complémentaires oraux ou écrits recelant la clef des livres taoïstes, sans laquelle le contenu de ces derniers demeurerait abscons, voire totalement incompréhensible. Mais mizhi peut également désigner des recettes alchimiques. Tao Hongjing 陶弘景 (456-536), dans son commentaire au Dengzhen yinjue 登真隱訣 (Instructions cachées pour sélever à [l'état de] Parfait), fait allusion à cette sorte de "directives secrètes" et ajoute cette injonction: “Il n'est pas permis d'en parler à la légère” 非可輕言 ${ }^{33}$. Il s'agit donc, en théorie, d'un savoir ésotérique. De ce fait, sa diffusion de maître à disciple est supposée obéir à des règles de stricte confidentialitéé ${ }^{34}$.

Le personnage auquel le titre rattache les Directives secrètes est également le locuteur dont émane le contenu du texte puisque celui-ci débute par l'expression: “Le Saint Seigneur dit" 聖君曰. L'appellation Shengjun renvoie ici à celle de Housheng Li jun 後聖李君 (“Seigneur $\mathrm{Li}$, Saint postérieur") et désigne une déité majeure du panthéon Shangqing, dotée d'identités et de fonctions variables, à caractère messianique et eschatologique, et qui est également l'un des avatars de Laozi $^{35}$. Le Saint Seigneur profere les Directives secrètes, mais le sous-titre

33) Dengzhen yinjue, HY 421, 3.23b; traduction dans Ursula-Angelika Cedzich, "Das Ritual der Himmelsmeister im Spiegel früher Quellen: Übersetzung und Untersuchung des liturgischen Materials im dritten chüan des Teng-chen yin-chüeb", thèse de la Julius-Maximilians-Universität, Würzburg, 1987, p. 149: "geheime Anweisungen, über die man nicht leichtfertig reden darf". Tao Hongjing aurait compilé ce texte entre 492 et 514 d'après les manuscrits autographes des révélations reçues par Yang Xi 楊羲 (330-386) entre 364 et 370; voir TC, p. 201-202, notice $n^{\circ} 421$; DT, p. 187-188, notice $n^{\circ} 0420$. Le premier juan du Dengzhen yinjue contient des instructions pour pratiquer la préservation de l'unité.

34) Sur ce sujet, voir Rolf A. Stein, "Aspects de la foi jurée en Chine", Annuaire du Collège de France, 67e année (1967): 411-415; Rolf A. Stein, "Textes taoïstes relatifs à la transmission des livres révélés", Annuaire du Collège de France, 68 année (1968): 453-457; Isabelle Robinet, "Nature et rôle du maître spirituel dans le taoïsme non liturgique", in Maître et disciples dans les traditions religieuses, éd. Michel Meslin, Paris, Cerf, 1990, p. 37-50.

35) Voir Anna Seidel, "The Image of the Perfect Ruler in Early Taoist Messianism: Lao-tzu and Li Hung", History of Religions 9, 2-3 (1969-1970): 216-247; Kobayashi Masayoshi 小 
$\mathrm{du}$ recueil attribue leur transmission (chuan 傳) au “Seigneur Garçon Vert” (Qingtong jun 青童君) ${ }^{36}$. Membre lui aussi du panthéon Shangqing, le Seigneur Garçon Vert est un intercesseur divin spécialisé dans la transmission des textes célestes aux hommes ${ }^{37}$. La préface canonique du Taiping jing, le Taiping jing fuwen $x u$, attribue au Seigneur Li et au Garçon Vert les deux premières places dans la ligne de transmission des "glyphes redoublés de la Grande paix" (Taiping fuwen 太本複文), un noyau scriptural en écriture divine dont découlerait le corpus révélé de la tradition ${ }^{38}$. On retrouve ces deux personnages en compagnie de trois autres divinités du panthéon Shangqing, avec lesquelles ils forment un dispositif symbolique quinaire, dans le premier juan du Taiping jing chao, juan "apocryphe" produit par le courant Shangqing et sans rapport avec les neuf autres ${ }^{39}$.

\section{Problèmes de paternité et de datation}

Revenons maintenant sur l'hypothèse sino-japonaise de la paternité des Directives secrètes. Dans le Canon des Ming, Lüqiu Fangyuan 閭丘方 遠, un ermite taoïste mort en 902, est crédité de la recension d'une

林正美, Rikuchō dōkyō-shi kenkyū 六朝道教史研究, Tōkyō, Sōbunsha, 1990, p. $456-461$.

36) Et non leur paternité, ce que laisse malencontreusement entendre la notice de TC, selon laquelle le recueil serait "signé" par le Seigneur Garçon Vert. Voir ci-après, Annexe 2, TRADUCTION INTÉGRALE, verset 1, n. 109 et 110.

37) Voir Kamitsuka, Rikuchō dökyō shisō no kenkyū, p. 123-148. Dans son sous-titre, le Jinque dijun sanyuan zhenyi jing, HY 253, 1a: 滑子授東海青童君, affirme avoir été conféré à ce même Seigneur Garçon Vert par Juanzi, ou l'inverse, selon Andersen, The Method of Holding the Three Ones, p. 39, "Transmitted to Juān-zi by the Green Youth of the Eastern Sea”. Juanzi est un immortel dont le Liexian zhuan 列仙傳 (Biographies d'immortels), HY 294, 1.5b, contient une biographie; voir sa traduction dans Max Kaltenmark, Le Lie-sien tchouan: Biographies légendaires des Immortels taoïstes de l'antiquité, $2^{\mathrm{e}}$ éd., Paris, Collège de France, Institut des hautes études chinoises, 1987 (éd. originale 1953), p. 68-71.

38) Taiping jing fuwen $x u$, HY 1093, Préface, 1a.

39) Taiping jing chao, 1.5b. Sur le caractère apocryphe de ce juan du Taiping jing chao, voir Wang Ming, “Lun Taiping jing chao jia bu zhi wei” 論太平經鈔甲部之猨, Lishi yuyan yanjiusuo jikan 18 (1948): 375-384; Li Gang 李剛, "Ye lun Taiping jing chao jia bu ji qi yu daojiao Shangqing pai zhi guanxi”也論太平經鈔甲部及其與道教上清派之關係, Daojia wenhua yanjiu 4 (1994): 284-299; Kameda Masami 龜田勝見, “Jōsei kösei dōkun rekki ni okeru shumin shisō ni tsuite: Taiheikyō-shō kōbu to no kankei o majiete” 上清後聖道 君列紀における種民思想について太平經鈔甲部との關係を交えて, Nippon Chügoku gakkaiho 50 (1998): 77-91. 
œuvre dont il attribue la version originale à Tao Hongjing, le Dongxuan lingbao zhenling weiye tu 洞玄靈寶真靈位業圖 (HY 167), et d'une présentation générale du courant Lingbao qualifiée de “chao" 鈔, le Taishang dongxuan lingbao dagang chao 太上洞玄靈寶大綱鈔 (HY 393). Selon sa biographie officielle, Lüqiu Fangyuan aurait pratiqué la préservation de l'unité et produit une “sélection" (quan 銓), ou un “commentaire” (quan 詮), du Taiping jing, en trente "chapitres" (pian 篇 $)^{40}$. Cette donnée, bien qu'elle ne recoupe la morphologie d'aucune œuvre connue de la Grande paix, passée ou présente, est généralement interprétée comme faisant référence au Taiping jing chao; mais ce texte est aujourd'hui divisé en 10 juan et non en 30 pian.

On peut souligner l'absence dans les Directives secrètes d'un thème fondamental du Taiping jing et du Taipingjing chao: le fardeau collectif et cumulatif des fautes humaines passées (chengfu 承負), dont les idéologues de la Grande paix souhaitent libérer l'humanité actuelle, à leurs yeux injustement affectée ${ }^{41}$. Or, le Taiping jing chao affirme que rien ne vaut la préservation de l'unité pour se libérer de ce fardeau ${ }^{42}$. Eu égard à l'importance du thème, on s'attendrait à ce que cette phrase (ou une variante) figure dans notre recueil. Cette lacune idéologique ne plaide pas en faveur de l'hypothèse d'une paternité commune des deux textes, même si elle est évidemment insuffisante pour l'infirmer.

Deux sources prouvent que notre recueil était en existence sous les Song du Nord 北宋 (960-1127). Vers la fin du XI siècle, dans le Youlong zhuan, Jia Shanxiang mentionne le Taiping jing chao et ajoute: "Il existe en outre des Directives secrètes de la Grande paix, en 1 juan, qui auraient été reçues par le Seigneur Garçon Vert, Conseiller suprême, et traitent

40) Xuxian zhuan 續仙傳 ( $x^{\mathrm{e}}$ s.), éd. Shen Fen 沈汾, HY 295, 3.4a-6a. Biographie reprise dans le Yunji qiqian 雲笈七籤 (vers 1028), éd. Zhang Junfang 張君房 (vers 961-vers 1042), HY 1026, 113B.29a-30b; Jia Shanxiang 賈善翔, Youlong zhuan 唒龍傳 (fin du XI s.), HY 773, 4.18b-19a; Lishi zhenxian tidao tongjian 歷世真仙體道通鑑 (fin du XIIr s.), éd. Zhao Daoyi 趙道一 ( $f$. 1297-1307), HY 296, 40.13b-15a; Xuanpin lu 玄品錄 (1335), éd. Zhang Tianyu 張天雨, HY 780, 5.7b-8a; Chuandeng 傳燈 (1554-1628), Tiantai shan fangwai zhi 天台山方外志 (1601), in Dazang jing bubian 大藏經補編, Taipei, Huayu chubanshe, 1984-1986, vol. 30, 9.12a-b.

41) Sur ce sujet, voir Barbara Hendrischke, "The Concept of Inherited Evil in the Taiping Jing”, East Asian History 2 (1991): 1-30; Kamitsuka, Rikuchō dōkyō shisō no kenkyū, p. 301-337.

42) Taiping jing chao, HY 1093, 3.3a (WM, p. 60): 欲解承負之責、莫如守一. Le passage correspondant du Taiping jing, plus long, n’a pas la même force. 
de la méthode de préservation de l'unité" 又有太平祕旨一卷、稱上 相青童君受、論守一之法 ${ }^{43}$. Deux siècles et demi plus tard, la liste d'œuvres de la catégorie des immortels divins 神仙類 annexée à celle des œuvres taoïstes 道家 dans l'histoire officielle de la dynastie des Song fait état de "Directives secrètes du Livre du Très-Haut, de Lüqiu Fangyuan, en 1 juan” 閭丘方遠太上經祕旨一卷, peut-être une référence corrompue à notre recueil ${ }^{44}$.

Est-il possible de remonter plus haut que l'époque des Song en examinant à présent le recueil lui-même? La visualisation de divinités corporelles - hors contexte liturgique - ayant progressivement évolué au cours des Tang vers des formes de contemplation intérieure (neiguan 內觀) ou de contemplation du vide (kongguan 空觀) plus ou moins adaptées de pratiques bouddhiques, puis vers l'alchimie intériorisée (neidan 內丹), il me semble que l'idéologie des Directives secrètes renvoie à des représentations et à des pratiques comparativement rudimentaires. En particulier, on ne trouve pas trace de ces développements philosophiques caractéristiques des courants et des textes taoïstes étudiés par E. Zürcher et I. Robinet et volontiers qualifiés de "bouddhisants". L'idéologie des versets me semble étrangère, et donc, est-on tenté de penser, antérieure, à la distinction cruciale opérée entre discipline mentale et discipline corporelle par les textes taoïstes "bouddhisants" à partir de cette période ${ }^{45}$.

Sans pousser davantage une contestable démonstration par la négative, je préfère m'en tenir à quelques exemples précis. La visualisation de lumières colorées et de divinités lumineuses, élément fondamental des

43) Jia Shanxiang, Youlong zhuan, HY 773, 4.18b.

44) Song shi 宋史 (1345), éd. Tuotuo 脫脫 (1313-1355), rééd. Beijing, Zhonghua shuju, 1977, 205.5196. Dans le titre en question, le caractère shang 上 serait une erreur pour ping 正.

45) Pour tout ce paragraphe, voir Erik Zürcher, The Buddhist Conquest of China: The Spread and Adaptation of Buddhism in Early China, Leiden, E. J. Brill, 1959; Erik Zürcher, "Buddhist Influence on Early Taoism: A Survey of Scriptural Evidence”, T'oung Pao 66, 1-3 (1980): 84-147; Isabelle Robinet, "Notes préliminaires sur quelques antinomies fondamentales entre le Bouddhisme et le Taoïsme", in Incontro di religioni in Asia tra il III ed il $X$ secolo d.C., éd. Lionello Lanciotti, Florence, Leo S. Olschki, 1984, p. 217-242; Isabelle Robinet, "De quelques effets du bouddhisme sur la problématique taoïste: Aspects de la confrontation du taö̈sme au bouddhisme", in Religion and Chinese Society, vol. 1, Ancient and Medieval China, éd. John Lagerwey, Hong Kong, The Chinese University, École française d'Extrême-Orient, 2004, p. 411-516. 
Directives secrètes, est incompatible avec les formes de méditation taoïste influencées par le bouddhisme qui visent à dépasser la pensée pour faire le vide. Au contraire, notre recueil considère comme un signe alarmant le fait de ne rien parvenir à visualiser au cours de la pratique (verset 13 dans ma traduction), ce qui est a priori contradictoire avec la notion bouddhique de vacuité totale. Autre exemple: deux versets déconseillent les états de conscience excessifs (23 et 35), mais leur vocabulaire et leur style sont bien éloignés des développements théoriques relatifs au contrôle émotionnel. Même constatation au niveau de la terminologie: on note l'occurrence isolée d'un syntagme qui pourrait éventuellement relever du lexique bouddhique, mais qui demeure sans conséquence sur le plan sémantique ${ }^{46}$.

En revanche, les Directives secrètes présentent des affinités avec le discours sur l'unité que tient Ge Hong dans le juan 18 du Baopu zi $i^{47}$. Dans ce passage, Ge Hong rapporte que son maitre Zheng Yin 鄭隱 (vers 215-vers 302) estimait que la préservation de l'unité constitue la plus performante des innombrables méthodes existantes pour garantir l'invulnérabilité. Pourtant, aux yeux de Ge Hong, préserver l'unité n'est qu'une méthode inférieure pour prolonger la longévité terrestre, seul le jindan 金丹 permettant de parvenir à l'ascension céleste ${ }^{48}$. Ge Hong compare l'efficacité de la "préservation de l'unité parfaite" 守真一, une sorte de pratique d'invulnérabilité individuelle, à celle de la "préservation de l'unité mystérieuse” 守玄一, sorte d'art de l'ubiquité, plus accessible, que son oncle Ge Xuan 葛玄 (164-244) aurait maîtriséé ${ }^{49}$. Or, si cette "préservation de l'unité parfaite" est absente de notre recueil, elle est mentionnée dans le Jinque dijun sanyuan zhenyi jing, où l'on trouve aussi plusieurs mentions de la préservation de l'unitéso.

46) Voir la traduction du verset 27, n. 144.

47) Voir James R. Ware (trad.), Alchemy, Medicine, Religion in the China of A.D. 320: The Nei P'ien of Ko Hung (Pao-p'u tzu), Cambridge (Mass.), Massachusetts Institute of Technology, 1966, p. 301-308; Kohn (trad.), The Taoist Experience, p. 198-204.

48) Baopu zi neipian, HY 1177, 18.3a. Il est admis que Ge Hong ne traite de la préservation de l'unité que dans la mesure où il s'agit de l'un des trois principaux courants représentatifs des traditions des régions situées au sud du Fleuve bleu.

49) Baоpu zi neipian, HY 1177, 18.4a-b.

50) Jinque dijun sanyuan zhenyi jing, HY 253, $2 \mathrm{~b}$ (2 occurrences de shou zhenyi) et 2a, 3a, 3b, $4 \mathrm{a}, 6 \mathrm{a}$ (6 occurrences de shouyi). 
Les Directives secrètes ne se réclament pas de l'alchimie de laboratoire ni de ses développements intériorisés. Les trois composantes subtiles du corps alchimique (shen 神, le divin, jing 精, l'essence, et $q i$ 氣, le souffle) appartiennent ici à l'arrière-plan théorique cosmologique et ontologique $^{51}$ et leur raffinement n'est pas envisagé. Mais, selon les spécialistes, la phase "embryonnaire" du développement historique du courant aujourd'hui appelé neidan 内丹 est si mal connue que l'hypothèse d'une parenté lointaine ne doit pas être exclue ${ }^{52}$. Après tout, certaines affinités entre l'idéologie du Taiping jing et celle de l'alchimie intérieure ont déjà été mises en lumière ${ }^{53}$. Mais le contenu et la forme des Directives secrètes les rapprochent plutôt des techniques de nutrition du principe vital (yangsheng 養生) ou de la nature interne (yangxing 養 性), antérieures à la fondation de l'Empire et très en vogue sous les $H_{a n}{ }^{54}$. Pour ce qui concerne le Huangting jing, la régularité de sa forme prosodique et sa terminologie spécialisée n'ont aucun équivalent dans les versets de notre recueil, qui ignore des concepts tels que les "trois unités" (sanyi 三一) et les trois “champs de cinabre" (dantian 丹田) qui leur sont associés ${ }^{55}$, ou encore le terme cun 存 pour désigner la visualisation ${ }^{56}$.

51) Voir Isabelle Robinet, "Jing, qi et shen", Revue Française d'Acupuncture 43 (1985): 27-36.

52) Pour un récent état de la question, voir Fabrizio Pregadio et Lowell Skar, "Inner Alchemy (Neidan)", in Daoism Handbook, éd. Livia Kohn, Leiden, E. J. Brill, 2000, p. 464-497.

53) Voir Zhang Guangbao 張廣保, “Taiping jing: neidan dao de chengli” 太平經一一內丹 道的成立, Daojia wenhua yanjiu 16 (1999): 123-150; Grégoire Espesset, "À vau-l'eau, à rebours ou l'ambivalence de la logique triadique dans l'idéologie du Taiping jing 太平經”, Cahiers d'Extrême-Asie 14 (2004): 61-95.

54) Voir Maspero, Le Taoïsme et les religions chinoises, p. 479-589; Sakade Yoshinobu, Dökyō to yōjo shiso 道教と養生思想, Tōkyō, Perikan-sha, 1992; Donald J. Harper, Early Chinese Medical Literature: The Mawangdui Medical Manuscripts, Londres et New York, Kegan Paul International, 1998, p. 110-147; Mark Csikszentmihảlyi, "Ethics and their relationship to self-cultivation practice", in Early Chinese Religion. Part One, éd. Lagerwey et Kalinowski, p. 519-542; Romain Graziani, "The subject and the sovereign: exploring the self in early Chinese self-cultivation", ibid., p. 459-517.

55) Notamment dans le Jinque dijun sanyuan zhenyi jing, HY 253, à partir de la p. 4a.

56) Ajoutons que, dans notre recueil, l'analogie du “nouveau-né" (chizi 赤子) relève davantage du registre ordinaire de la langue que de la terminologie de la physiologie taoïste (verset 55). Concernant l'occurrence isolée de mingtang 明堂 (Palais de la clarté), voir la traduction du verset 51, n. 165; Long Hui (éd.), Taiping jing quanyi, p. 1544, n. 8, l'assimile abusivement au Palais Niwan 泥丸宮, palais central dans le dispositif des Neuf palais 九宮 et espace occupant le centre de la tête dans la physiologie du Shangqing. Le Palais 
Quelle que soit l'identité exacte du bibliographe taoïste qui a réuni une soixantaine d'extraits du Taiping jing sous la forme du recueil de versets que nous connaissons, l'impact idéologique du courant Shangqing semble se limiter aux noms et aux appellations de divinités insérés dans le titre, le sous-titre et le début du premier verset. Cette "mise aux normes" strictement formelle mise à part, le contenu des Directives secrètes semble témoigner d'une certaine fidélité au texte maître de la tradition, ce qui suggère que leur matériau de base est bien antérieur à la période à laquelle, selon les deux sources citées plus haut, le recueil était en circulation. Nous aurions donc bien affaire à un élément tardif plutôt qu'apocryphe du corpus de la Grande paix.

\section{Sources et recoupements}

Tournons-nous à présent vers les sources de notre document, en commençant par le Taiping jing, puisqu'il figure dans son titre même. Une quinzaine de versets recoupent le Taiping jing ou le Taiping jing chao, ou les deux simultanément, ainsi que le manuscrit de Dunhuang S.4226. Un autre verset recoupe une citation du Taiping jing dans l'encyclopédie Taiping yulan 太平御覽 ${ }^{57}$. La filiation littéraire revendiquée par le titre du recueil est ainsi confirmée. Si une majorité de versets ne recoupent pas le Taipingjing du Canon taoïste, c'est parce que cette version est incomplète ${ }^{58}$. Concernant le Taiping jing chao, le problème des choix éditoriaux ayant présidé à son élaboration n’a toujours pas été élucidé. À la lumière du contenu du Taiping jing et de la table des matières de $\mathrm{S} .4226$, il s'agirait d'une version expurgée, souvent réécrite, du texte maître, dans laquelle des passages couvrant plusieurs pages ont été condensés en quelques lignes. Certains titres sont amalgamés au corps du texte, amputés de toute numérotation mais

Niwan est bien mentionné, par contre, dans le Jinque dijun sanyuan zhenyi jing, HY 253, 4b-5b et 7a, et la formation du "nouveau-né" y est le résultat d'un long processus de transformations successives dont l'aboutissement est l'ascension céleste du pratiquant (4a); voir infra, n. 112; Andersen, The Method of Holding the Three Ones, p. 43-48.

57) Pour le détail des recoupements, voir Annexe 1, Tableau Des Recoupements.

58) Une comparaison de cette version avec la table des matières du manuscrit $S .4226$ suggère qu'environ deux tiers du texte ont été perdus; voir Espesset, "Le manuscrit Stein 4226 Taiping bu juan di er dans l'histoire du taoïsme médiéval”, p. 202 et p. 247, Annexe II, Tableaux D et E. 
fréquemment identifiables. Quant aux passages absents du Taipingjing chao, soit ils ont été volontairement omis, soit ils manquaient déjà dans la version du Taiping jing ayant servi de source à l'auteur du résumé.

Une dizaine de chapitres de la version canonique du Taiping jing abordent le thème de la préservation de l'unité, seul ou combiné avec d'autres ${ }^{59}$. Une comparaison systématique des titres contenant le syntagme dans le manuscrit S.4226, le Taiping jing et le Taiping jing chao (titres amalgamés au corps du texte dans ce dernier cas) révèle que six chapitres étaient consacrés à ce thème dans la version rééditée vers la fin des Six dynasties (Tableau A). Dans la version actuelle, le seul à porter un titre construit autour du syntagme est le chapitre 152: "Préserver l'unité, entrer dans l'oratoire et connaître les divinités" 守一 入室知神 ${ }^{60}$.

Tableau A. Comparaison des titres de chapitres du Taiping jing contenant le syntagme shouyi d'après trois sources du corpus de la Grande paix

\begin{tabular}{|c|c|c|}
\hline MS S.4226 & Taiping jing & Taiping jing chao \\
\hline $\begin{array}{l}\text { 清身守一法第十五 } \\
\text { (col. 77) }\end{array}$ & - & 清身 ... 守一 (10.6a-b) \\
\hline 偹一却邪第廿一 $\left(\right.$ col. 84) ${ }^{61}$ & - & 偹一却邪 (2.2a) \\
\hline $\begin{array}{l}\text { 守一明之法第廿七 } \\
\text { (col. 90) }\end{array}$ & - & 守一明之法 (2.5a) \\
\hline 守一法第卅九 (col. 103) & [守一]? (37.7a) & 守一 (3.3a) \\
\hline $\begin{array}{l}\text { 守一入室知神戒百五十二 } \\
\text { (col. 172) }\end{array}$ & $\begin{array}{l}\text { 守二入室知神戒第一百五 } \\
\text { 十二 }(96.5 \mathrm{~b})\end{array}$ & 守一 ... 入室 (6.22b) \\
\hline $\begin{array}{l}\text { 守一長存決三百十五 } \\
\text { (col. 262) }\end{array}$ & - & 守一 ... 長存 (9.19a) \\
\hline
\end{tabular}

Accessoirement, ce tableau comparatif suggère qu'une partie du contenu du chapitre 49, intitulé dans S.4226 "Méthode pour préserver l'unité" (col. 103), a été amalgamée à la fin du chapitre 48, dont la

59) Voir Hendrischke, The Scripture on Great Peace, p. 147-150, n. 9.

60) Taiping jing, HY 1093, 96.5b (WM, p. 409).

61) Le résumé correspondant à ce chapitre dans le Taiping jing chao (HY 1093, 2.2a-3a; WM, p. 12-13) contient trois occurrences de shouyi et traite bien de la préservation de l'unité. 
dernière page est entièrement consacrée à ce thème ${ }^{62}$. Le chapitre 50 (début du juan 39) suit directement le chapitre 48 (fin du juan 37) dans la séquence canonique, et une note en tête du juan 39 indique que le juan 38, contenant le chapitre 49, “manque": 原缺三十八卷 ${ }^{63}$. Ce phénomène, fréquent dans le Taiping jing canonique, invite à un réexamen général de sa structure littéraire, projet qui déborde le cadre du présent travail.

Â part ces recoupements internes au corpus de la Grande paix, les éditions critiques, index et bases de données permettent de rapprocher le contenu de notre recueil d'autres textes et, à travers eux, des sources incontournables de la littérature chinoise, dont le Laozi et le Zhuangzi. Les versets 41, 50, 57 et 58 empruntent au Laozi les syntagmes shenqi 神器, “instrument divin”, buzai 不宰, “ne pas faire preuve d'autorité”, jiushi 久視, qui exprime l'idée de vision pérenne ou de perpétuité, et genshen 根深, la “racine profonde” (shengen 深根 dans le Laozi), tandis que la seconde moitié du dernier verset constitue une extrapolation du chapitre $39 \mathrm{du}$ Laozi $^{64}$. Les versets 53 (不望其報, 6b) et 57 (不言而 理、功成不幸, 6b-7a), entre autres, recoupent plusieurs éléments de l'exégèse qui s'est constituée autour du Laozi: mentionnons le commentaire attribué à Heshang gong ${ }^{65}$, un autre commentaire de l'époque des Tang ${ }^{66}$, et le sous-commentaire de Du Guangting 杜光庭 (850-933) à celui de l'empereur Xuanzong 玄宗 (r. 713-756) ${ }^{67}$.

La phrase finale du recueil (子知一萬事畢矣, 7a) recoupe effectivement le Taiping jing ${ }^{68}$, mais cette occurrence paraît renvoyer à l'un des “chapitres extérieurs" (waipian 外篇) du Zhuangzi ${ }^{69}$, source à

62) Taiping jing, HY 1093, 37.7a-b (WM, p. 60-61).

63) Taiping jing, HY 1093, 39.1a (WM, p. 63, n. 1).

64) A Concordance to the Laozi 老子逐字索引, éd. D. C. Lau, Hong Kong, The Commercial Press, 1996, 10A/4/2, 29A/10/10, 39A/14/3-4, 51A/17/16, 59A/20/10-11.

65) Daode zhenjing zhu, HY 682, 1.2b: 不望其報.

66) Daode zhenjing xinzhu 道德真經新註, par Li Yue 李約 ( $f$. 810), HY 692, 3.8a: 功成 不幸. Pour la paternité et la date du commentaire, voir TC, p. 288, notice $\mathrm{n}^{\circ} 692$; DT, p. 300, notice $\mathrm{n}^{\circ} 0687$.

67) Daode zhenjing guangsheng yi 道德真經廣聖義 (préface datée de 901), HY 725, 39.13b: 不言而理. L'occurrence intervient dans le sous-commentaire de Du, signalisé par le caractère $y i$ 義; voir TC, p. 293-294, notice $\mathrm{n}^{\circ} 725$; DT, p. 313-314, notice $\mathrm{n}^{\circ} 0719$.

68) Taiping jing, HY 1093, 92.5a: 子知守一萬事畢 (WM, p. 369).

69) Zhuangzi ( $\mathrm{IV}^{\mathrm{e}}-\mathrm{II}^{\mathrm{e}}$ s. av. n. è.), en partie par Zhuang Zhou 莊周 (vers 370-301 av. n. è.), chapitre 12, “Tiandi” 天地, citant une source écrite non identifiée (“ji”記): 通於一而萬 事畢; A Concordance to the Zhuangzi 莊子逐字索引, éd. D. C. Lau, Hong Kong, The 
laquelle puisent, directement ou indirectement, la version exotérique du Huangting jing ${ }^{70}$, le Baopu $z i^{71}$ et toute la littérature taoïste postérieure, riche en occurrences analogues ${ }^{72}$. S'il ne s'agit pas d'un emprunt direct, le dernier tiers du verset 40 (臥在山西、反知山東, $5 \mathrm{a}$ ) et le commentaire d'un vers de l'une des versions exotériques du Huangting jing ${ }^{73}$ doivent remonter à une source commune, ce qui pose une nouvelle fois la question des échanges entre les traditions du Livre de la Cour jaune et du Livre de la Grande paix. Des origines sociales différentes et des audiences spécifiques expliquent probablement, au moins en partie, l'écart manifeste entre la terminologie spécialisée du premier et le champ lexical relativement limité, pour ne pas dire pauvre, du second ${ }^{74}$.

Le verset 25 débute par trois lieux communs sur la longévité et l'immortalité: le rajeunissement en dépit de l'âge (老而更少), le noircissement des cheveux blanchis (髮白更黑) et la repousse des dents tombées (齒落更生, 3b). On retrouve les deux derniers motifs, à quelques variantes près, dans un grand nombre de textes taoïstes, alchimiques ou médicaux. Pour nous en tenir à la littérature taoïste

Commercial Press, 2000, 12/29/17; traduction dans Angus C. Graham, Chuang-Tzü: The Seven Inner Chapters and Other Writings from the Book Chuang-tzu, Londres, George Allen \& Unwin, 1981, p. 269: "Everywhere be conversant with the One, and the myriad tasks will all be done." Selon Graham, p. 28 et 257-258, ce chapitre serait le fait d'éditeurs "syncrétistes" qui auraient compilé le Zhuangzi au II ${ }^{\mathrm{e}}$ siècle avant notre ère. L'illumination du visage au verset 45 (面目有光明) pourrait aussi provenir du Zhuangzi; A Concordance to the Zhuangzi, 29/87/10: 面目有光; traduction dans Graham, Chuang-Tzú, p. 236: “your countenance glows".

70) Taishang huangting waijing yujing (antérieur à 255?), HY 332, $2.1 \mathrm{a}$ : 子能知之萬事畢. Le vers ne contient pas le syntagme shouyi, mais le commentaire de Liangqiu zi 梁丘子 (Bo Lüzhong 白履忠, fl. 722-729), in Xiuzhen shishu 修真十書 (vers 1340), HY 263, 59.2a, débute ainsi: “Cultiver la Voie et préserver l'unité...” 修道守一. Par ailleurs, ce commentaire cite à deux reprises le Taiping jing (Xiuzhen shishu, HY 263, 55.26a, 57.18a).

71) Baopu zi neipian, HY 1177, 18.1a: 人能知一萬事畢, 3a: 能知一則萬事畢.

72) Kohn, "Guarding the One", p. 131, n. 7, énumère des recoupements avec onze sources.

73) Taishang huangting waijing jing 太上黃庭外景經, commenté par Wucheng zi 務成子 (non identifié; époque Tang?), in Yunji qiqian, HY 1026, 12.36a: 臥於山西、知於山東. Cette occurrence intervient dans le commentaire d'un vers où il est question pour l'adepte d'entrer en contact avec les divinités, tout comme dans notre recueil.

74) Le champ lexical du Taiping jing se limite à 2127 mots dont l'indice de répétition semble exceptionnellement élevé; voir Grégoire Espesset, "Cosmologie et trifonctionnalité dans l'idéologie du Livre de la Grande paix (Taiping jing 太平經)", thèse de l'Université Paris VII, Paris, 2002, p. 77-80. Le recueil des Directives secretes est trop bref (1 771 caractères) pour que l'étendue de son champ lexical et l'indice de répétition de ses mots soient mesurables selon la même méthode. 
canonique, citons le Liexian zhuan, prototype du genre hagiographique ${ }^{75}$, le Taishang Lao jun zhongjing 太上老君中經 (Livre du centre du très haut seigneur $L a o)^{76}$, le Baopu $z i^{77}$, le Taishang lingbao wufu xu 太上靈 寶五符序 (Préface aux cinq talismans du trésor spirituel) ${ }^{78}$ et le commentaire de Bo Lüzhong à la version ésotérique du Huangting jing $^{79}$.

Le cas des neuf versets 14 à 22 (2a-3a) mérite une attention particulière. En effet, ces versets n'obéissent pas au modèle prévalant dans le reste du recueil: ils ne traitent pas de la préservation de l'unité et ne contiennent donc pas le syntagme shouyi, mais tous débutent par un syntagme ordinal, de “premier" (di yi 第一) à “neuvième” (di jiu 第 九). Or, ces versets recoupent bien le Taiping jing et le résumé correspondant dans le Taiping jing chao ${ }^{80}$. Mais leur examen révèle surtout des similarités troublantes avec un texte totalement extérieur au corpus de la Grande paix, le Zhengyi fawen taishang wailu yi 正一 法文太上外籙儀 (HY 1233), produit vers la fin des Six dynasties par l'église du Maître céleste (Tianshi dao 天師道) ${ }^{81}$. Ce texte, qui traite des règles présidant à l'octroi des registres d'ordination aux fidèles, un sujet a priori sans rapport avec le Taiping jing, le cite pourtant explicitement à plusieurs reprises, et en plusieurs endroits il présente avec lui des

75) Liexian zhuan, traditionnellement attribué à Liu Xiang 劉向 (77-6 av. n. è.), HY 294, 1.3b: 髮白更黑、齒落更生; traduction de ce passage et variantes dans Kaltenmark, Le Lie-sien tchouan, p. 55-56. Sur les problèmes de datation que pose ce texte, voir TC, p. 114, notice $\mathrm{n}^{\circ} 294$; DT, p. 131-132, notice $\mathrm{n}^{\circ} 0293$.

76) Taishang Lao jun zhongjing, HY 1160, 2.5b: 白髮復黑、齒落更生. Sur ce texte, qui paraît antérieur à Ge Hong, voir TC, p. 92-94, notice $\mathrm{n}^{\circ} 1168$; DT, p. 565, notice $\mathrm{n}^{\circ}$ 1158.

77) Baopu zi neipian, HY 1177, 4.12a: 髮白還黑、齒落更生, 11.19b: 髮白更黑、齒墮更 生.

78) Taishang lingbao wufu xu, HY 388, 2.8a: 白髮復黑、齒落重生, 2.28b: 齒落重生、髮 白更黑 et 2.30a: 白髮更黑、齒落重生. Sur ce texte peut-être composé vers la fin du III ${ }^{\mathrm{e}}$ siècle mais dont la version canonique comporterait des passages interpolés, voir Gil Raz, "Creation of Tradition: The Five Talismans of the Numinous Treasure and the Formation of Early Daoism”, thèse de l'Indiana University, Bloomington, 2004. Cf. TC, p. 232-233, notice $\mathrm{n}^{\circ} 388$, et DT, p. 173-174, notice $\mathrm{n}^{\circ} 0387$, pour d'autres éléments de datation.

79) Huangting neijing yujing zhu 黃庭内景玉經註 (VIII ${ }^{\mathrm{e}}$ s.), par Liangqiu zi (Bo Lüzhong), HY 402, 3.11b: 髮白反黑、齒墮更生.

80) Taiping jing, HY 1093, 71.2a-3a; Taiping jing chao, HY 1093, 5.5a-b (WM, p. 282-284).

81) Voir DT, p. 603, notice $n^{\circ} 1231$; TC, p. 132-133, notice $\mathrm{n}^{\circ} 1243$. Pour le détail de ces similarités, se reporter aux notes accompagnant la traduction des versets nº 14 à 22 . 
"affinités" certaines, comme le signale K. Schipper dans sa notice. Étant donné que c'est le Zhengyi fawen taishang wailu yi qui cite le Taiping jing et jamais l'inverse, il est tentant d'interpréter ces similarités comme autant d'emprunts implicites du premier au second: la leçon du Zhengyi fawen taishang wailu yi pourrait être un résumé ou une adaptation de celle du Taiping jing. L'histoire littéraire de ces deux textes est cependant trop mal connue pour qu'on puisse affirmer avec certitude la direction des emprunts; qui plus est, les deux textes peuvent découler d'une source commune.

Quoi qu'il en soit, cette occurrence troublante pose une nouvelle fois la question des rapports entre la tradition de la Grande paix et l'église du Maître céleste au cours de la période des Six dynasties ${ }^{82}$. Selon une citation du corpus scripturaire de l'Unité orthodoxe de la fin de cette période ou du début des Tang, en l'an 142 de notre ère le Très-Haut 太 上 aurait révélé à Zhang (Dao) Ling 張道陵, parmi d'autres documents, un Taiping dongji zhi jing 太本洞極之經 (Livre de la Grande paix suprêmement pénétrante) en 144 juan ${ }^{83}$. La même citation ajoute qu'il convient de distinguer ce texte d'un autre également en circulation et de teneur comparable, un Taiping jing en 170 juan, transmis jadis par le Seigneur Lao 老君 à un certain Gan Ji 干吉 durant le règne du roi Nan 郝王 (314-256 av. n. è.), dernier souverain des Zhou 周 ${ }^{84}$. Trois siècles plus tard, les compilateurs du Yunji qiqian citent le même

82) K. Schipper suggère que des membres des deux mouvements ont pu se rencontrer en Chine du Sud au début du Iv $v^{e}$ siècle, hypothèse qui repose sur l'identification de la Voie de la Grande paix au mouvement des rebelles qui se sont soulevés en 184 de notre ère et qui sont désignés sous le nom de "Turbans jaunes" (buangjin 黃巾) dans les sources officielles; voir Kristofer Schipper, La religion de la Chine: La tradition vivante, Paris, Fayard, 2008, p. 144-145.

83) Zhengyi jing 正一經 (vie-VII ${ }^{\mathrm{e}}$ s.?), cité dans Meng Anpai 孟安排 (fl. 699), Daojiao yishu 道教義樞, HY 1121, 2.9b. Voir Maeda, Shoki dōkyō kyōten no keisei, p. 42-54.

84) Ibid. Dans le corpus de l'église du Maître céleste, la plus ancienne occurrence connue de cette révélation à Gan Ji durant le règne du dernier souverain Zhou remonterait à la fin du III ${ }^{\mathrm{e}}$ siècle, dans le "Dadao jia lingjie" 大道家令戒 (après 255), in Zhengyi fawen tianshi jiaojie kejing 正一法文天師教戒科經, HY 788, 13a. Sur la question de l'historicité du rapport de ce Gan (ou Yu 于) Ji avec le Taiping jing et la tradition de la Grande paix, voir Fukui, Dökyō no kisoteki kenkyū, p. 68-77; Kandel, Taiping jing. The Origin and Transmission of the "Scripture on General Welfare", p. 32-40; Jens Østergard Petersen, "The Early Traditions Relating to the Han Dynasty Transmission of the Taiping jing", Acta Orientalia (Copenhague) 50 (1989): 133-171; 51 (1990): 173-216; Maeda, Shoki dōkyō kyōten no keisei, p. 17-37. 
matériau, mais ils jugent opportun de préciser que le Taiping dongji zhi jing est désormais perdu ${ }^{85}$. Deux Livres de la Grande paix auraient ainsi coexisté pendant un laps de temps indéterminé, l'un incorporé au canon de l'église du Maître céleste, l'autre "redécouvert" par le courant Shangqing. Cette coexistence contribuerait à expliquer la présence de strates textuelles distinctes dans les éléments du corpus scripturaire de la Grande paix.

\section{Structure littéraire et analyse interne}

Si l'on excepte la séquence de neuf versets dont il vient d'être question, la structure répétitive des versets rappelle celle des titres de chapitres dans le Taiping jing. Que ce soit dans la version canonique ou dans le manuscrit S.4226, chaque titre complet peut se décomposer en un énoncé thématique initial, un indicateur médian, et un ordinal; par exemple, le titre 守一法第井九 dans S.4226 (col. 103) se décompose en “Préserver l'unité” 守一 (énoncé thématique initial), “méthode” 法 (indicateur médian), ${ }^{86}$ et “ $n^{\circ} 49$ ” 第冊九 (ordinal). Or, si l'on ne tient pas compte de l'ordinal, l'énoncé thématique initial et l'indicateur médian qui le suit composent la séquence 守一法, formule que l'on retrouve en tête de 29 versets du recueil (25-27, 31-34, 36-39 et 41-58 dans ma traduction). La même manipulation, appliquée au titre du chapitre 27 (S.4226, col. 90), donne 守一明之法, formule figurant en tête du seul verset 2, mais sous la variante 守一明法 en tête de 9 autres versets (4 et 6-13). La formule initiale de 49 des 58 versets qui composent les Directives secrètes semble donc correspondre à l'énoncé thématique initial suivi de l'indicateur médian dans les titres de chapitre du Taiping jing. D'une certaine manière, la structure type de ces versets dérive de la structure littéraire du texte maître de la tradition.

On peut émettre l'hypothèse que cette formule a été conçue à l'intention du lecteur pour baliser visuellement le recueil autant que pour en scander la récitation, pour remplir une fonction à la fois

\footnotetext{
85) Yunji qiqian, HY 1026, 6.15b-16a.

86) Dans le Taiping jing, les indicateurs médians les plus nombreux sont fa 法 ("méthode") et jue 訣 (“instruction”, orthographié 決 dans S.4226); quelques autres, dont jie 戒 ("précepte"), sont beaucoup plus rares. Voir Espesset, "Le manuscrit Stein 4226 Taiping bu juan di er dans l'histoire du taoïsme médiéval”, p. 196 et p. 244, Annexe II, Tableau A.
} 
rythmique et mnémonique. Le fait que la formule semble parfois faire partie intégrante du contenu sémantique du verset — c'est le cas, par exemple, dans les versets 3 et 5 - n'est nullement en contradiction avec cette double fonction. L'hypothèse selon laquelle le recueil était initialement destiné à être mémorisé en vue d'une récitation pourrait être confirmée par le fait qu'une proportion importante des versets obéit à une versification syllabique. Exception faite d'une séquence heptamètre isolée dans le tout dernier verset du recueil, le rythme est très majoritairement tétrasyllabique, style ancien qui évoque le Shijing 詩 經. Quinze versets sur 58 sont entièrement composés de tétrasyllabes (versets 27, 28, 31, 33-36, 39-40, 42-44, 48, 53, 57), tandis que dans une douzaine d'autres cas un seul vers par verset échappe à ce mètre (versets 4, 6, 9, 11-12, 30, 37-38, 41, 45, 47, 54). Autre élément évoquant la mémorisation et la récitation: la présence de rimes dans une moitié au moins des versets du recueil (versets 1, 3-7, 27-28, 32-37, $40-48,50,52-56,58)^{87}$. Dans quelques cas ces rimes présentent l'intérêt de fournir des indices supplémentaires concernant la datation du matériau de base du recueil. L'association de rimes en hun 魂 (gen 根, men 門) et en zhen 真 (shen 神) dans les versets 33 et 50 refléterait un usage spécifique de l'époque des Han ou des Trois royaumes 三國 (220-265), ces deux groupes de caractères cessant ensuite de rimer $^{88}$. De même, les caractères wai 外, hai 害 et shi 世 (verset 27) ne riment que dans la poésie des Han (rime en $j i$ 祭), le troisième caractère quittant le groupe des deux premiers à partir de l'époque des Trois royaumes ${ }^{89}$. Et si you 尤 rime avec zhuan 專 et qian 遷 (verset 32) dans la poésie des Han (rime en $z h i$ 之), le caractère intègre la rime you 幽 à partir de l'époque des Jin 晉 $(265-316)^{90}$. Par contre, dans le verset 36, shou 守 et hou 候 ne riment (en you 幽) qu’à partir de la poésie des Wei 魏

87) Pour les groupes de rimes antérieurs aux premiers "livres de rimes" ( $y u n s h u$ 韻書) connus, je me base sur la reconstitution réalisée par Luo Changpei 羅常培 et Zhou Zumo 周祖謨, Han Wei Jin Nanbei chao yunbu yanbian yanjiu 漢魏晉南北朝韻部演變研究, vol. 1, Beijing, Kexue chubanshe, 1958, p. 125-245. Pour la reconstitution phonétique correspondante, on peut consulter William H. Baxter, A Handbook of Old Chinese Phonology, Berlin, Mouton de Gruyter, 1992, p. 562-564, Table 10.125.

88) Zhou Zumo 周祖謨, Zhou Zumo yuyan wenshi lunji 周祖謨語言文史論集, Hangzhou, Zhejiang guji chubanshe, 1988, p. 112-113.

89) Ibid., p. 122-123.

90) Ibid., p. 160-161. 
(220-265 $)^{91}$. Pour finir, il faut préciser que l'énumération occupant les versets 14 à 22 n'est pas rimée.

Un découpage en cinq parties peut être opéré dans le contenu du recueil pour rendre compte des variations thématiques que sa lecture met en évidence; mais ce découpage à but purement heuristique ne rend pas justice à la fluidité du texte chinois, dans lequel les transitions entre ces parties se font le plus souvent de façon naturelle, comme nous aurons l'occasion de le constater. Voici néanmoins la façon dont se distinguent ces cinq parties.

I. Le paragraphe introductif (verset 1) décrit sommairement l'arrièreplan théorique du recueil, dans lequel les triades ciel-terre-homme 天 地人 (ou ciel-terre-harmonie centrale 天地中和) et divin-essencesouffle 神精氣 occupent une place prépondérante. D’origine et de nature cosmiques, le divin, l'essence et le souffle font un et interagissent en permanence, autant à l'échelle macrocosmique qu'en chaque être vivant. La pratique s'inscrit sur cette toile de fond qui reflète l'idéologie triadique du texte maître de la tradition ${ }^{92}$. Dans ce verset, la définition physiologique de ce que veut dire "préserver l'unité" est aussi importante que le contexte théorique: "Préserver le souffle en l'unissant au divin, (faire en sorte que) l'essence ne quitte pas le corps, et unifier ces trois (instances) en pensée” 守氣而合神、精不去其形、念此三合以爲一 $(1 \mathrm{a})^{93}$. Cette phrase longue de 17 caractères, qui débute par le mot shou 守 et s'achève par le mot $y i$ 一, constitue la définition "développée" du binôme éponyme de la pratique. Pour finir, le verset développe l'idée de visualisation interne du corps grâce à une lumière dont l'intensité s'accroît à proportion de la concentration du pratiquant, thème qui introduit la seconde partie du recueil.

II. La seconde partie (12 versets, $\mathrm{n}^{\circ} 2$ à 13 ) décrit, et parfois commente, ce que l'on visualise en pratiquant une première méthode, intitulée "préserver l'unité de la luminosité" et consistant à illuminer le corps de

91) Ibid., p. 127-128.

92) Voir Espesset, "À vau-l'eau, à rebours".

93) Cette formulation de l'unité triadique semble devoir beaucoup au chapitre 14 du Lao$z i$, dans lequel une formule analogue est appliquée aux trois qualités de la Voie, $y i$ 夷 (invisible), $x i$ 希 (inaudible) et $w e i$ 微 (impalpable): 此三者不可致詰、故混而爲一. 
l'intérieur. Avant la concentration, toute lumière est absente (verset 2); puis apparaît à l'intérieur du corps une luminosité dont l'intensité varie et la couleur change selon les correspondances des cinq agents (versets 5-12). Le pratiquant jalonne ainsi l'espace et le temps symboliques dans lesquels il opère. En gagnant la totalité du champ corporel, la luminosité attire une foule de divinités que le pratiquant peut contrôler (versets 3 et 4) et qui lui permettront de diviniser son corps. L'étape ultime de la pratique consiste, après l'extension de cette luminosité hors du corps, à la ramener à soi en l'unifiant et à la contenir dans l'abdomen (versets 5 et 12). Le dernier verset $\left(n^{\circ} 13\right)$ met en garde contre l'obscurcissement total du corps, à l'intérieur comme à l'extérieur, symptôme alarmant qui nécessite l'absorption urgente de remèdes et la recherche des sept premiers "principes" d'une liste subséquemment donnée.

III. Séquence à part autant par le fond que par la forme, la troisième partie (9 versets, $\mathrm{n}^{\circ} 14$ à 22) consiste en une liste de neuf "principes" (shou 首) dont chacun est successivement nommé puis décrit. Trois occurrences de $c i$ 次 (versets 16, 17 et 19) suggèrent que la liste obéit au moins en partie à une logique classificatoire descendante ${ }^{94}$. Les thèmes de la méditation et de la visualisation de l'espace corporel (versets 14-16) et des divinités qui le fréquentent (versets 17-18) trouvent un prolongement dans les cinq premiers "principes" de la liste. Les quatre derniers (versets 19-22) s'apparentent davantage à des mises en gardes relatives à certaines catégories d'êtres surnaturels que le pratiquant pourrait être amené à rencontrer (au cours de l'exercice, présume-t-on): toutes sortes de divinités, ainsi que des mânes ancestraux, "Yin pur" 純 陰. Cette partie se caractérise par la variété du panthéon qu’elle met en

94) Dans le Taiping jing, HY 1093, 71.1a-4a (WM, p. 281), le passage correspondant à cette énumération apparait dans le chapitre intitulé "Instruction n ${ }^{\circ}$ 107: Texte sur les avantages et les désavantages des neuf principes de la Voie parfaite” 真道九首得失文訣第 一百七, qui explique que "la Voie comprend neuf degrés" 道有九度. Chaque degré se subdivise en neuf principes, pour un total de 81 principes, organisés en " $3 \times 9=27$ principes supérieurs” (其上三九二十七者), “ $3 \times 9=27$ principes médians” (其中央三九二十 七者) et “3 $\times 9=27$ principes inférieurs” (其下三九二十七者); Taiping jing, HY 1093, $71.1 \mathrm{~b}$ (WM, p. 282). Dans le Zhengyi fawen taishang wailu yi, HY 1233, 15b, il s'agit de "neuf mérites" (jiu gong 九功) que les pratiquants sont invités à acquérir en fonction de leurs capacités propres. 
scène, monde divin dont le pratiquant peut obtenir des avantages individuels (versets 17-18), mais qui représente aussi une menace, en particulier de perversion, xie 邪 (versets 19-21) ${ }^{95}$.

IV. La quatrième partie, la plus longue du recueil avec 35 versets ( $\mathrm{n}^{\circ} 23$ à 57), est entièrement consacrée à la "voie de la préservation de l'unité". La plupart de ces versets mêlent une exaltation récurrente de l'efficacité de la méthode, véritable panacée, à des conseils d'ordre pratique et à des mises en gardes. Le but ultime de la pratique semble être de contrôler l' "instrument divin" (shenqi) ${ }^{96}$, image du corps sublimé par ses divinités résidentes, afin d'obtenir le Tao (verset 50). État de conscience interprété comme un signe positif dans le contexte de la première méthode, la joie ( $x i$ 喜) doit être ici explicitement dépassée (verset 35), ce qui suggère que la seconde méthode s'adresse à des pratiquants d'un niveau avancé. Les deux méthodes présentent néanmoins des similitudes: illumination du corps (versets 27 et 45) et rôle prépondérant du divin (occurrences de shen dans 20 versets sur 35), notamment des divinités corporelles (versets 33, 36, 40 et 48) ou chargées de la surveillance de la conduite humaine (versets 49 et 51) ${ }^{97}$. À ce stade, il s'agit surtout de voir et d'illuminer les divinités (versets 47 et 52). Les notions morales, notoirement absentes de la séquence de versets consacrés à la première méthode, deviennent ici récurrentes:

95) Le Taiping jing, HY 1093, 71.1b-2a, affirme au sujet des trois degrés inférieurs que "ces voies comportent de nombreuses perversions, ces esprits ne peuvent pas être employés constamment”, 其道多耶 (= 邪) 、其神精不可常使 (WM, p. 282). Même avertissement dans le Zhengyi fawen taishang wailu yi, HY 1233, 16b: "Du sixième mérite au neuvième, ces pratiques comportent de nombreuses perversions. ( $\mathrm{Si}$ ) on n'observe pas résolument les préceptes, on ne pourra que succomber à la foule des démons. Les méthodes de ces trois degrés inférieurs de la Voie sont très dangereuses” 自六功至九、其事多邪、不精持戒、 必陷魔群、道之下品、有此三階、法甚危險.

96) Le Taiping jing chao, HY 1093, 10.9a (WM, p. 727), définit cet “instrument divin” comme étant constitué par l'union indissociable du divin, de l'essence et du corps (xing 形, la “forme sensible"). Dans le Baopu zi neipian, HY 1177, 19.5a, Ge Hong mentionne un Tianshi shenqi jing 天師神器經 (Livre de l'instrument divin du Maître céleste), et le Yunji qiqian, HY 1026, 47.9a, parle de “préserver l'unité de l'instrument divin” 守一神器. Dans la langue des sources officielles, le syntagme shenqi désigne le sceau impérial ou les insignes de la souveraineté.

97) Sur l'importance de ce thème dans une partie du corpus de la Grande paix, voir Grégoire Espesset, "Criminalized Abnormality, Moral Etiology, and Redemptive Suffering in the Secondary Strata of the Taiping jing", Asia Major, $3^{\mathrm{e}}$ série, 15, 2 (2002): 1-50. 
cinq versets (23-24, 48, 50 et 52) mentionnent la bonté (shan 善), associée dans le verset 24 à la bienveillance (en 恩). Le pratiquant doit faire preuve d'humilité (verset 43) et de frugalité (versets 37 et 44). Son humanité (ren 仁), sa bienfaisance ( $h u i$ 惠), sa droiture (zhong 忠) et sa dévotion filiale (xiao 孝) doivent être désintéressées (verset 53) ${ }^{98}$.

V. Le paragraphe final (un seul verset, $\mathrm{n}^{\circ} 58$ ) récapitule l'importance fondamentale de l'unité en énumérant dix exemples de l'efficacité de sa préservation au niveau individuel, en termes de longévité, de santé et d'harmonie cosmique (dissipation des désastres), mais aussi d'ordre social et de pratique cultuelle. Pour créer un effet de contraste, neuf exemples sont ensuite donnés des effets catastrophiques qu'entraînerait la perte de l'unité par les entités cosmiques - le ciel et la terre, le soleil, la lune et les astres - et par les monts, les cours d'eau, les divinités et les hommes.

\section{Conclusion}

Dans le Taiping jing, le Maître céleste (tianshi 天師) chargé par le ciel de prêcher la révélation de la Grande paix affirme que la préservation de l'unité compose une partie importante de ses écrits, et que ceux-ci ne sont pas différents des textes anciens et actuels qui traitent de la méthode ${ }^{99}$. Ce discours est, au moins en partie, destiné à séduire une audience déjà familiarisée avec ce type de pratiques et qui exige peutêtre des garanties pour accepter la nouvelle révélation. Un disciple rappelle avoir recherché "les méthodes de préservation de l'unité et de nutrition de la nature interne, pour un total de 300 principes” 守一養 性之法、凡三百首 avant que les discours du maître ne l'eussent

98) Le Jinque dijun sanyuan zhenyi jing, HY 253, 6a-7b, comporte lui aussi un passage intitulé "méthode de préservation de l'unité" 守一之法. La méthode qui y est décrite présente cependant d'importantes différences d'ordre technique avec celle de notre recueil. La pratique, qui doit suivre le rythme quaternaire du cycle saisonnier, inclut des incantations (zhou 呪) à psalmodier; le pratiquant est invité à faire entrer les divinités dans son corps par la bouche, etc.; voir Andersen, The Method of Holding the Three Ones, p. 39-63; Maspero, Le Taoisme et les religions chinoises, p. 401-403. L'arrière-plan cosmologique de la pratique et le panthéon qu'elle met en ouvre sont bien plus complexes que ce que l'on observe dans le cas des Directives secrìtes.

99) Taiping jing, HY 1093, 96.4b, 5b-6a (WM, p. 408 et 410). 
converti. Or, c'est dans ces pages que le maître classe la préservation de l'unité avec les choses superficielles (fuhua 浮華), suggérant qu'il considère la méthode comme un enseignement de base destiné à être dépassé ${ }^{100}$. De fait, les références à la méthode de préservation de l'unité dont il émaille ses sermons en font souvent une étape préliminaire indispensable en vue de l'obtention de la Voie. Son utilité est, par exemple, de connaître ses manquements en termes de moralité ou de réfléchir sur ses fautes pour régénérer son lot de vie. En d'autres termes, la méthode est intégrée à l'apprentissage religieux du néophyte ${ }^{101}$. Ainsi, il est logique que la tradition de la Grande paix et son corpus ne soient pas prioritairement associés aux méthodes de préservation de l'unité. Et, de fait, quand Tao Hongjing évoque dans le Dengzhen yinjue les spécialistes de ce type de méthode (shouyi jia 守一家), c'est après avoir précisé que c'est le Suling jing 素靈經, un texte n'ayant pas encore été révélé (littéralement “ne circulant pas encore dans le monde”, 未行於 世), qui en constitue “la base fondamentale” (zong ben 宗本) ${ }^{102}$.

Sur le plan de l'histoire idéologique de la tradition de la Grande paix, le thème de la préservation de l'unité permet aussi de comprendre comment le problème de l'ambivalence de la logique triadique à l'œuvre dans le Taiping jing a été résolu. Dans un passage traitant de méditation en isolement, le Taiping jing chao affirme que "préserver la trinité ne vaut pas préserver la dualité, préserver la dualité ne vaut pas préserver l'unité” 守三不如守二、守二不如守一103. Pour l'auteur de ce texte,

\footnotetext{
100) Taiping jing, HY 1093, 102.1a, 2a (WM, p. 459-460).

101) Taiping jing, HY 1093, 39.1b-2a, 96.8b, 96.19b, 96.20a et 112.4b (WM, p. 64, 421-422, 412 et 566).

102) Dengzhen yinjue, HY 421, 1.3a, 1.10b. Les trois textes de base relatifs à la "méthode de la trinité”三一之法 qu'énumère le Jinque dijun sanyuan zhenyi jing, HY 253, 3a, sont le Dadong zhenjing 大洞真經, le Dayou miaojing 大有妙經 et le Taishang suling 太上素靈; voir Andersen, The Method of Holding the Three Ones, p. 42. Sur ces textes centraux du corpus du Shangqing, voir Isabelle Robinet, "Le Ta-tung chen-ching: Son authenticité et sa place dans les textes du Shang-ch'ing ching", in Tantric and Taoist studies in honour of Rolf A. Stein, vol. 2, éd. Michel Strickmann, Bruxelles, Institut belge des hautes études chinoises, 1983, p. 394-433; Mugitani Kunio, “Daidō shinkyō sanjūkyū-shō o megutte” 大洞真 經三十九章おめぐつて, in Chügoku ko dōkyō shi kenkyū 中国古道教史研究, éd. Yoshikawa Tadao 吉川忠夫, Kyōto, Dōhōsha, 1992, p. 55-87.

103) Taiping jing chao, HY 1093, 10.6b (WM, p. 724). L'analyse du manuscrit S.4226 a montré que le juan 10 du Taiping jing chao renferme un résumé des juan 1 à 17 du Taiping jing, absents dans la version canonique. Ce passage du Taiping jing chao ne peut donc pas être confronté au texte maître.
} 
c'est bien la logique de reconquête de l'unité qui l'emporte sur la logique de déclin. L'idéologie triadique, encapsulée par la triade divin-essencesouffle, impose au texte ses pratiques discursives, mais en tant que constat de l'état des choses. Au cœur même de ce dispositif triadique total, c'est l'unité indissociable de chaque triade qui assure la cohésion d'ensemble du système. Sur ce point précis, la convergence idéologique du Taiping jing chao et de notre recueil plaide en faveur d'une paternité commune.

Le recueil des Directives a indubitablement été compilé à partir d'une sélection thématique opérée dans une version du Taiping jing dont les strates textuelles les plus anciennes pourraient remonter aux $\mathrm{II}^{\mathrm{e}}$ et $\mathrm{III}^{\mathrm{e}}$ siècles de notre ère, comme le suggère l'analyse des rimes. Ce matériau de base, qui expose des pratiques distinctes de celles dont il est question dans le Ваори zi, véhicule une idéologie vierge de toute influence bouddhique et indépendante des représentations physiologiques du courant Shangqing. Le compilateur du recueil a complété ce matériau ancien avec des emprunts au corpus exégétique constitué autour des œuvres taoïstes classiques — dont le Laozi — sur une période s'étendant jusqu’à la fin des Tang, ce qui s’accorde avec la datation suggérée par l'hypothèse des spécialistes chinois et japonais; pour autant, l'identité du responsable de la compilation demeure impossible à confirmer ou à infirmer.

L'identité des divinités mentionnées en tête de notre recueil reflète la récupération de la tradition de la Grande paix par le courant taoïste Shangqing vers la fin de la période des Six dynasties. Trois autres sources du corpus de la tradition intègrent également des éléments tirés de la biographie du Seigneur Li, Saint Postérieur (Housheng Lijun 後聖李 君): la narration refermant la table des matières du Taiping jing dans S.4226, la préface canonique du Taiping jing, et le juan premier du Taiping jing chao ${ }^{104}$. L'occurrence parmi ces éléments de certains thèmes de prédilection du courant Shangqing ${ }^{105}$ invite à penser que cette

104) Ces éléments sont empruntés au Shangqing housheng daojun lieji 上清後聖道君列紀 (HY 442) et au Huangtian Shangqing jinque dijun lingshu ziwen shangjing 皇天上清金閭 帝君靈書紫文上經 (HY 639), deux œuvres du Shangqing originel; voir Robinet, La révélation du Shangqing dans l'histoire du taoïme, vol. 2, p. 101-110; TC, p. 150-153, notices $\mathrm{n}^{\circ} 639$ et $\mathrm{n}^{\circ} 442$; DT, p. 197-198, notice $\mathrm{n}^{\circ} 0441$, et p. 277 , notice $\mathrm{n}^{\circ} 0634$.

105) Manuscrit S.4226, col. 295-346 (traduction dans Espesset, "Le manuscrit Stein 4226 Taiping bu juan di er dans l'histoire du taö̈sme médiéval”, p. 238-243): cataclysme lors 
récupération eut pour toile de fond les spéculations messianiques et apocalyptiques qui se développèrent au cours de la période ${ }^{106}$. Dans le cas des Directives secrètes, le seul impact visible du processus est l'ajout des mentions de deux divinités du panthéon Shangqing dans le titre, le sous-titre et le début du premier verset. Une telle récupération ne signifie donc pas que le matériau originel a nécessairement subi une réécriture en profondeur.

Durkheim voyait dans l'ascendant religieux une simple particularisation de l'autorité morale de la société107. Il paraît incontestable que l'expérience religieuse de la préservation de l'unité s'inscrit dans un système totalisant de représentations monistes ayant des implications non seulement morales, mais aussi politiques et sociales, cosmologiques, épistémologiques, etc. Il est dès lors naturel qu'un discours érigeant l'unité en panacée ait eu un impact profond lors de périodes de division de l'entité nationale comme celles qui firent suite à l'effondrement de l'empire des Han et à celui de l'empire des Tang, ou encore après le repli de la dynastie des Song sur le Sud. D'un autre côté, le même discours peut être interprété comme un éloge vibrant de l'unité triomphante, comme une glorification de l'unité politique réalisée ou restaurée ${ }^{108}$. C'est dans ce contexte d'alternance que doivent s'appréhender les Directives secrètes du Saint Seigneur du Livre de la Grande paix, recueil

d'une année jiashen 甲申; parousie du Saint Seigneur “le sixième jour du deuxième mois de l'année renchen” 壬辰之年二月六日; anéantissement des hommes corrompus et salut du peuple élu, semence de l'humanité régénérée (zhongmin 種民). Taiping jing fuwen xu, HY 1093, Préface, 2b (WM, p. 745): parousie du Saint Seigneur lors de l'année renchen. Taipingjing chao, HY 1093, 1.1a-5a (WM, p. 1-5): cycles du "Yang-Neuf" et du "Cent-Six" 陽九百六; cataclysmes lors d'années jiashen majeures et mineures 大小甲申; parousie du Seigneur Li “le sixième jour du troisième mois de l'année renchen” 壬辰之年三月六日; salut du peuple élu, etc.

106) Sur ce sujet, voir, entre autres, Kristofer Schipper, "Millénarismes et messianismes dans la Chine ancienne", in Understanding Modern China. Problems and Methods, éd. Lionello Lanciotti et Piero Corradini, Roma, Centro Ricerche Sinologiche, Istituto Italiano per il Medio ed Estremo Oriente, 1979, p. 31-49; Anna Seidel, “Taoist Messianism”, Numen 31 (1983): 161-174; Christine Mollier, Une apocalypse taoïste du $V^{e}$ siècle: Le Livre des Incantations Divines des Grottes Abyssales, Paris, Collège de France, Institut des hautes études chinoises, 1990; Stephen R. Bokenkamp, “Time After Time: Taoist Apocalyptic History and the Founding of the T'ang Dynasty", Asia Major, $3^{\mathrm{e}}$ série, 7 (1994): 59-88.

107) Émile Durkheim, L'individualisme et les intellectuels, 1898, rééd. Paris, Mille et une nuits, 2002.

108) Je remercie Barend ter Haar pour cette suggestion (correspondance privée). 
qui témoigne à la fois de la pérennité d'une tradition en définitive mal connue et de son évolution au gré des vicissitudes de l'Histoire.

\section{Annexe 1: Tableau des recoupements}

\begin{tabular}{|c|c|c|}
\hline \multicolumn{2}{|c|}{ HY 1094} & \multirow{2}{*}{ Recoupements } \\
\hline versets & pages.lignes & \\
\hline $\mathrm{n}^{\circ} 1$ & $1 \mathrm{a} .3-7$ & Taiping jing chao, HY 1093, 10.10a-b \\
\hline$n^{\circ} 4-6$ & 1b.9-2a.3 & Taiping jing chao, HY 1093, 2.5a-b \\
\hline$n^{\circ} 14-22$ & $2 b .5-3 b .3$ & $\begin{array}{l}\text { Taiping jing, HY 1093, 71.2a-3a } \\
\text { Taiping jing chao, HY } 1093,5.5 \mathrm{a}-\mathrm{b} \\
\text { Zhengyi fawen taishang wailu yi, HY 1233, 15b-16a }\end{array}$ \\
\hline$n^{\circ} 23$ & $3 b .4-6$ & Taiping jing, HY 1093, 96.5b-6a \\
\hline $\mathrm{n}^{\circ} 24$ & $3 b .7-8$ & Taiping jing, HY 1093, 96.6a \\
\hline $\mathrm{n}^{\circ} 25$ & 3b.9 & Liexian zhuan, HY 294, 1.3b (etc.) \\
\hline $\mathrm{n}^{\circ} 31$ & $4 \mathrm{a} .9$ & Taiping jing chao, HY 1093, 2.3a \\
\hline $\mathrm{n}^{\circ} 33$ & $4 \mathrm{~b} .5$ & Taiping jing chao, HY 1093, 2.3a \\
\hline \multirow{2}{*}{$\mathrm{n}^{\circ} 37$} & $5 \mathrm{a} .2$ & Baopu zi neipian, HY 1177, 18.1a \\
\hline & $5 a .3-5$ & Taiping jing, cité dans Taiping yulan, 668.1a \\
\hline $\mathrm{n}^{\circ} 38$ & $5 \mathrm{a} .6$ & Taiping jing chao, HY 1093, 2.3a \\
\hline \multirow[b]{2}{*}{$\mathrm{n}^{\circ} 40$} & $5 \mathrm{a} .8$ & Baopu zi neipian, HY 1177, 18.2b \\
\hline & $5 a .8-9$ & $\begin{array}{l}\text { Taishang huangting waijing jing, in Yunji qiqian, HY 1026, } \\
\text { 12.36a }\end{array}$ \\
\hline$n^{\circ} 43$ & $5 b .2$ & $\begin{array}{l}\text { Taiping jing chao, HY 1093, 5.11b, 6.10a } \\
\text { Baopu zi waipian, HY 1179, 2.3b }\end{array}$ \\
\hline \multirow[t]{2}{*}{$n^{\circ} 45$} & $5 b .5$ & $\begin{array}{l}\text { Taiping jing, HY 1093, 116.6a } \\
\text { Taiping jing chao, HY 1093, 7.35b }\end{array}$ \\
\hline & 5 b. $5-6$ & Zhuangzi, 29/87/10 \\
\hline $\mathrm{n}^{\circ} 47$ & $5 b .9-10$ & Taiping bu juan di er, MS S.4226, col. 294 \\
\hline $\mathrm{n}^{\circ} 53$ & $6 \mathrm{~b} .2$ & Daode zhenjing zhu, HY 682, 1.2b (etc.) \\
\hline$n^{\circ} 56$ & $6 b .8$ & $\begin{array}{l}\text { Taiping jing, HY 1093, 50.2a, 98.11a, 98.12b } \\
\text { Taiping jing chao, HY 1093, 3.6a, 3.27b, 6.28a, 7.19b } \\
\text { Baopu zi neipian, HY 1177, 9.2b (etc.) }\end{array}$ \\
\hline \multirow{2}{*}{$\mathrm{n}^{\circ} 57$} & $6 b .10$ & Daode zhenjing guangsheng yi, HY 725, 39.13b \\
\hline & 6b.10-7a.1 & Daode zhenjing xinzhu, HY 692, 3.8a \\
\hline
\end{tabular}




\begin{tabular}{|c|c|c|}
\hline \multicolumn{2}{|c|}{ HY 1094} & \multirow{2}{*}{ Recoupements } \\
\hline versets & pages.lignes & \\
\hline \multirow[b]{2}{*}{$\mathrm{n}^{\circ} 58$} & 7a.6, 9 & $\begin{array}{l}\text { Laozi, 39/14/3-4 } \\
\text { Baopu zi neipian, HY 1177, 18.1a }\end{array}$ \\
\hline & $7 a .10$ & $\begin{array}{l}\text { Taiping jing, HY 1093, 92.5a } \\
\text { Zhuangzi, 12/29/17 } \\
\text { Taishang huangting waijing yujing, HY 332, 2.1a } \\
\text { Baopu zi neipian, HY 1177, 18.1a, 3a (etc.) }\end{array}$ \\
\hline
\end{tabular}

\section{Annexe 2: Traduction intégrale}

[1a] Directives secrètes du Saint Seigneur du Livre de la Grande paix. Transmises ${ }^{109}$ par le Seigneur Garçon Vert, Conseiller suprême ${ }^{110}$.

(1) Le Saint Seigneur dit: Ensemble, les trois souffles font un. L'un est essence, l'un est divin, l'un est souffle. Tous trois occupent le même rang, au fondement de la racine des souffles du ciel, de la terre et de l'homme. Le divin est reçu du ciel; l'essence est reçue de la terre; le souffle est reçu de l'harmonie centrale ${ }^{111}$. Associés les uns aux autres, ils constituent l'unité. Ainsi le divin se déplace en chevauchant le souffle et l'essence se tient en leur centre. À trois, ils s'entraident pour assurer l'ordre. Celui qui aspire à la longévité doit aimer le souffle, honorer le divin et estimer l'essence. Car le souffle, dont procède l'homme à l'origine, est engendré par le chaos; le souffle engendre l'essence, l'essence engendre le divin, le divin engendre la luminosité. (Leur) origine est dans les souffles du Yin et du Yang, qui se changent en essence; l'essence se change en divin; le divin se change en luminosité ${ }^{112}$. Celui qui aspire à la longévité doit préserver le souffle en

109) La leçon du texte est $f u$ 傅, “mentor dans une maison princière" (Charles O. Hucker, A Dictionary of Official Titles in Imperial China, Stanford, Stanford University Press, 1985, p. 216, $\mathrm{n}^{\circ}$ 2031). Mais fu étant immédiatement suivi du titre du Seigneur Garçon Vert, il est clair qu'il s'agit d'une erreur pour chuan 傳, comme l'a remarqué Fukui, Dōkyō no kisoteki kenkyū, p. 248.

110) Shangxiang 上相. Sur ce titre, voir Hucker, A Dictionary of Official Titles in Imperial China, p. 408, n 4998.

111) Zhonghe 中和. Dans l'idéologie ternaire du Taiping jing, l'harmonie centrale est, à l'intérieur de la triade, la troisième instance produite par l'union harmonieuse du Yin et du Yang. À son tour, l'union harmonieuse du Yin, du Yang et de l'harmonie centrale produit l'harmonie suprême, taihe 太和; voir Espesset, “À vau-l'eau, à rebours", p. 72-73.

112) Cf. Jinque dijun sanyuan zhenyi jing, HY 253, 4a: "Le souffle se condense en essence, l'essence est émue et devient le divin, le divin se transforme en enfançon, l'enfançon monte et devient un Parfait, le Parfait s'élève et devient nouveau-né. C'est l'unité parfaite" 氣結爲精、精感虏神、神化爲嬰兒、嬰兒上爲真人、真人升爲赤子、此真一也. Voir Andersen, The Method of Holding the Three Ones, p. 43. 
l'unissant au divin, (faire en sorte que) l'essence ne quitte pas (son) corps, et unifier ces trois (instances) en pensée. [1b] À la longue, il voit distinctement le centre de sa personne, le corps s'allège graduellement, l'essence augmente en luminosité et (sa) clarté est de plus en plus raffinée ${ }^{113}$. Dans l'esprit se fait une grande tranquillité, une gaieté comparable à la joie, et le souffle de la Grande paix ${ }^{114}$ y répond. Perfectionner l'intérieur ayant des répercussions sur l'extérieur, à l'intérieur on atteint la longévité et à l'extérieur on atteint l'ordre. Sans effort, on atteint spontanément la Grande paix.

(2) Méthode pour préserver l'unité de la luminosité. Quand on n'est pas encore concentré, les yeux clos on ne voit que ténèbres, l'œil ne perçoit aucune clarté115.

(3) Préservez l'unité encore et encore, et il se produit spontanément une lumière. On voit distinctement les quatre secteurs et l'on circule au loin en suivant la luminosité. On voit entièrement la configuration de son propre corps. Une multitude de divinités vont s'assembler et l'on sera ainsi capable de diviniser son corps.

(4) La méthode pour préserver l'unité de la luminosité est la racine d'une longévité étendue. On peut conduire ${ }^{116}$ les myriades de divinités hors de la porte de la lumière.

(5) Préservez l'unité. Quand vous êtes concentré sur une luminosité semblable au feu naissant, préservez-la soigneusement sans la perdre. Au début rouge écarlate, [2a] puis d'un blanc sans mélange, elle devient verte à la longue. Pénétrez cette luminosité totalement et, du plus lointain, faites-la revenir en régulant son unité. À l'intérieur il n'est rien qui ne soit lumineux, les cent indispositions sont expulsées. Préservez-la sans relâche, vous transcenderez la durée de la vie humaine ${ }^{117}$.

(6) Méthode pour préserver l'unité de la luminosité, semblable à la luminosité du soleil levant, à la luminosité du soleil à son zénith.

(7) Méthode pour préserver l'unité de la luminosité. Si la luminosité est d'un vert sans mélange, verte et pure, c'est la luminosité du Petit Yang.

(8) Méthode pour préserver l'unité de la luminosité. Si la luminosité est d'un rouge écarlate sans mélange comme la lumière du feu, on transcendera la durée de la vie humaine.

113) Jing 精 désigne autant l'idée de raffinement que l'essence (l'une des trois composantes de la triade dont il est question tout au long de ce paragraphe initial), la concentration (versets 2 et 5 ) et, dans le dernier verset ( ${ }^{\circ} 58$ ), la brillance de la lune.

114) Taiping qi 太本氣. Dans le Taiping jing, le souffle de la Grande paix procède de l'harmonie suprême (taihe 太和); voir supra, n. 111.

115) Kohn, The Taoist Experience, p. 195, ajoute ici qu'il suffit de s'asseoir tranquillement ("just sit quietly") et parle d'un "œil interne" ("inner eye"), deux idées absentes du texte chinois mais que la traductrice ne signale pas comme étant ses propres ajouts.

116) Yu 御. Leçon du passage correspondant du Taiping jing chao, HY 1093, 2.5a (WM, p. 16): $z u$ 祖, "suivre les traces de".

117) Dushi 度世. L'expression revient dans les versets 8 et 58 ci-après. 
(9) Méthode pour préserver l'unité de la luminosité. Si la luminosité est d'un jaune sans mélange et pure ${ }^{118}$, c'est la clarté de l'harmonie centrale. C'est un excellent remède de la Voie.

(10) Méthode pour préserver l'unité de la luminosité. D’un blanc sans mélange comme de l'eau pure, c'est la luminosité du Petit Yin.

(11) Méthode pour préserver l'unité de la luminosité. Si la luminosité est d'un noir sans mélange, pure comme de l'eau observée à travers une petite ouverture, c'est la clarté du Grand Yin ${ }^{119}$. [2b]

(12) Méthode pour préserver l'unité de la luminosité. Si les quatre directions sont obscures et le centre de l'abdomen totalement illuminé, c'est la luminosité de l'harmonie suprême, Voie de la grande conformité.

(13) Méthode pour préserver l'unité de la luminosité. Si l'extérieur et l'intérieur (du corps) sont obscurs, s'il n'y a rien à quoi se raccrocher ni rien de visible, le pratiquant ${ }^{120}$ est dans une confusion fâcheuse. Se hâter de l'aider en lui prescrivant des remèdes et (en faisant que), à l'intérieur de lui-même, il recherche les sept premiers principes (de la liste ci-dessous) et tende vers eux.

(14) Premier (principe). Souffle primordial sans interférence ${ }^{121}$. Réfléchir à sa personne sans une seule interférence ${ }^{122}$. Pénétrer seulement la totalité de sa personne en pensée, comme une accumulation de souffle sans corporalitéér. Quand ce sera fait, il n'y aura rien d'infaisable, rien d'inconnu ${ }^{124}$.

118) Lire qing 清 pour qing 青, comme nous y invite le parallélisme entre ce verset et le verset 7. Même correction dans Yu (éd.), Taiping jing zhengdu, p. 560.

119) La séquence des versets 7 à 11 correspond à celle des Cinq agents — Est, Sud, Centre, Ouest, puis Nord — selon le système d'engendrement mutuel (xiangsheng 相生). John Lagerwey me signale que cette séquence est aussi celle du Taishang lingbao wufu xu (HY 388), mais que les textes du Shangqing obéissent en général à une séquence qui s'achève par le centre (correspondance privée).

120) Ci ren 此人, littéralement "cet homme", celui qui pratique.

121) Yuanqi wuwei 元氣無爲. Materia prima cosmique, souffle primordial à l'origine de toute chose, yuanqi est un concept central dans la pensée des Han et les spéculations taoïstes; voir Maspero, Le Taoïme et les religions chinoises, p. 465-468.

122) Wu yi wei 無一爲. J'insère wei, suivant les leçons concordantes du Taiping jing, HY 1093, 71.2a, et du Taiping jing chao, HY 1093, 5.5a (WM, p. 282).

123) Weiqi wuxing 委氣無形, attribut de la catégorie supérieure dans la hiérarchie humaine en base neuf décrite par le Taiping jing, HY 1093, 42.1a (WM, p. 88) et le Taiping jing chao, HY 1093, 4.15b (WM, p. 222). Cette similarité suggère que la hiérarchie humaine en base neuf et l'énumération des neuf principes répondent, au moins en partie, à la même logique classificatoire.

124) Cf. Zhengyi fawen taishang wailu yi, HY 1233, 15b: "Premier (mérite). Exhorter chacun (à avoir) les mêmes aspirations, réfléchir à sa personne sans interférer, pénétrer totalement sa personne en pensée (comme) une accumulation de souffle sans corporalité" 一者、勸 諸同志、念身無爲、思身洞白、委互無形. 
(15) Deuxième (principe). Il s'agit de la spontanéitée ${ }^{125}$ du néant. Préserver le corps, et le centre de la personne s'illumine de haut en bas comme du jade sans défaut. C'est l'image du souffle primordial qui n'interfère pas $^{126}$.

(16) Troisième (principe). Dénombrement. Se concentrer longtemps et retourner son regard vers soi. Dénombrer (les parties du corps), des cheveux aux cinq doigts de (chaque) pied, en distinguant l'intérieur et l'extérieur de la configuration du corps, sans rien omettre ${ }^{127}$. Méditer ainsi constamment. [3a] On appelle (ce principe) suite du néant ${ }^{128}$.

(17) Quatrième (principe). Méditer sur les allées et venues des divinités des cinq organes et visualiser leurs déplacements. Il est possible de leur parler et de pouvoir connaitre le faste et le néfaste. (Ce principe) fait suite au dénombrement ${ }^{129}$.

(18) Cinquième (principe). Les divinités de la Voie majeure. Les divinités humaines sortent (du corps) puis s'apparient aux cinq agents et aux quatre saisons. Vertes, jaunes, blanches et noires ${ }^{130}$, elles sont entièrement identiques aux divinités des organes. Elles vont et viennent, quittent et réintègrent (le corps). En employant les fonctionnaires divins des cinq agents et des quatre saisons, on peut mater les cent perversités ${ }^{131}$.

(19) Sixième (principe). Percer ${ }^{132}$ la félicité ${ }^{133}$. Attaquer en les perçant ${ }^{134}$ les

125) Ziran 自然, littéralement "tel par soi-même", notion parfois rapprochée du sponte sua de Lucrèce. Voir Liu Xiaogan, "Naturalness (Tzu-jan), the Core Value in Taoism: Its Ancient Meaning and its Significance Today", in Lao-tzu and the Tao-te-ching, éd. Livia Kohn et Michael LaFargue, Albany, State University of New York Press, 1998, p. 211-228.

126) Cf. Zhengyi fawen taishang wailu yi, HY 1233, 16a: "Second (mérite). Préserver le corps vide et lumineux, comme du jade sans défaut” 二者、守形虛白、若玉無瑕.

127) Mo bi bei zhi 莫畢備之. Ma traduction s'inspire des leçons concordantes du Taiping jing, HY 1093, 71.2b, et du Taiping jing chao, HY 1093, 5.5a (WM, p. 282): 莫不畢數.

128) Cf. Zhengyi fawen taishang wailu yi, HY 1233, 16a: "Troisième (mérite). Se concentrer longtemps, intérioriser (son) regard, et dénombrer (toutes les parties du corps, des) cheveux jusqu'aux pieds”三者、積精內視、數髮至足.

129) Cf. Zhengyi fawen taishang wailu yi, HY 1233, 16a: "Quatrième (mérite). Méditer sur les divinités des cinq organes, les visualiser et leur adresser la parole” 四者、思五藏神、 見與言語.

130) La leçon correspondante du Taiping jing, HY 1093, 71.2b, qui n'est pas tétrasyllabe, inclut la couleur rouge ( $c h i$ 赤), complétant ainsi le système quinaire (WM, p. 284). Le Taiping jing chao, HY 1093, 5.5a, donne “vertes, rouges, jaunes et noires" 青赤黃黑 (ibid.).

131) Cf. Zhengyi fawen taishang wailu yi, HY 1233, 16a: "Cinquième (mérite). En pensée, convoquer les divinités corporelles et employer les quatre saisons et les cinq agents” 五者、 念召體神、使四時五行.

132) Lire $c i$ 刺 pour $c i$ 次, d'après les leçons concordantes du Taiping jing, HY 1093, 71.2b, et du Taiping jing chao, HY 1093, 5.5b (WM, p. 284). Voir aussi la n. 134 ci-dessous.

133) $X i$ 喜, obstacle à la vision de l'unité, au même titre que la colère $(n u)$, ainsi que le précise le verset 23 ci-après.

134) Lire $c i$ 刺 pour la 刺. Le mot suggère l'emploi d'une arme blanche — probablement une épée — dans le contexte d'un rituel d'exorcisme. 
divinités du Tao de la terre ${ }^{135}$ qui font aimer les séductions et entrer à moitié dans la perversité $e^{136}$.

(20) Septième (principe). Intrigues des dieux du sol. Le ciel, la terre, les quatre saisons, les dieux du sol et des céréales, les monts et les rivières: sacrifier à ces divinités conduit les hommes à entrer en contact avec elles et à s'impliquer dans des déviances perverses. Ils courent à leur perte sans rien obtenir ${ }^{137}$. [3b]

(21) Huitième (principe). Divinités innombrables. Ces divinités sont de toutes sortes. On ne peut pas se rattacher à leur Voie. Elles font proférer aux hommes des paroles déviantes. Pour moitié, elles sont parfaites; pour moitié, elles sont perverses ${ }^{138}$.

(22) Neuvième (principe). Les ancêtres. Yin pur, ce ne sont pas des Parfaits. Toutes (les entités) qui répondent ne sont que des mânes ${ }^{139}$.

(23) Voie de la préservation de l'unité. Prenez ceux qui ont préservé l'unité dans le passé et le présent, puis regroupez-les par catégories. Les sages supérieurs qui la préservent transcendent la durée de la vie humaine. Les sages moyens qui la préservent sont d'excellents ministres et de bons fonctionnaires pour le souverain.

135) Didao shen 地道神, divinités mineures, notamment par opposition à dadao shen 大道 神, les "divinités de la Voie majeure" du cinquième principe (verset 18).

136) Cf. Zhengyi fawen taishang wailu yi, HY 1233, 16a: "Sixième (mérite). Faire une offrande aux six jia, (préparer?) le talisman des huit fonctionnaires, et percer les divinités de la terre” 六者、醮六甲、八吏符、刺 (=刺) 地神. Les six jia sont des divinités calendaires associées à l'année de naissance et les huit fonctionnaires, les divinités des huit trigrammes (bagua八卦). Les rites taoïstes correspondant à ces divinités découleraient de pratiques divinatoires antérieures à l'émergence de la religion taoïste; voir Gil Raz, "Time Manipulation in Early Daoist Ritual: The East Well Chart and the Eight Archivists", Asia Major, $3^{\text {e }}$ série, 18, 2 (2005): 27-65. Une "offrande aux six jia" est attestée dans la littérature taoïste canonique, par exemple dans le Taishang zhuguo jiumin zongzhen miyao 太上助國 救民總真祕要 (préface datée de 1116), par Yuan Miaozong 元妙宗, HY 1217, 7.18a; sur les rapports du juan 7 de ce texte avec d'anciens rituels du taoïsme Zhengyi 正一 (Unité orthodoxe), voir TC, p. 1057-1060, notice $n^{\circ} 1227$. Un "talisman des huit fonctionnaires" devait être absorbé ( $f u$ 服) dans le cadre d'un rituel pour la fabrication d'une épée magique décrit dans le Huangdi taiyi bamen nishun shengsi jue 黃帝太一八門逆順生死訣, HY 588, $17 \mathrm{a}-\mathrm{b}$, un ouvrage anonyme qui remonterait à la fin des Tang ou à la période des Cinq dynasties, selon DT, p. 256, notice $\mathrm{n}^{\circ} 0583$.

137) Cf. Zhengyi fawen taishang wailu yi, HY 1233, 16a: "Septième (mérite). Prendre à son service les dieux du sol et des céréales, et la foule des divinités des monts et des rivières" 七 者、役使社稷、山川眾神.

138) Cf. Zhengyi fawen taishang wailu yi, HY 1233, 16a: "Huitième (mérite). S'exercer à étendre les souffles essentiels et formuler des présages concernant le vrai et le faux"八者、 習延精昰、占說是非.

139) Cf. Zhengyi fawen taishang wailu yi, HY 1233, 16a: "Neuvième (mérite). Invoquer les mânes et (les) interroger au sujet du faste et du néfaste” 九者、呼鬼、問以吉凶. 
Les moins doués ${ }^{140}$ qui la pratiquent ne connaissent plus la joie ni la colère ${ }^{141}$, et le monde est sans ressentiment.

(24) Préserver l'unité, c'est la préserver avec profit ${ }^{142}$. La bonté se répand dans toutes les directions de l'espace ${ }^{143}$ et la bienveillance rejoint les desseins du ciel et de la terre.

(25) Méthode pour préserver l'unité. On rajeunit malgré la vieillesse, les cheveux blancs redeviennent noirs, les dents tombées repoussent. Si on préserve (l'unité) un mois, on augmente la longévité d'une année; deux mois, de deux années, et ainsi de suite. [4a]

(26) Méthode pour préserver l'unité. Commencer à penser en s'isolant dans un lieu dont les cloisons doivent être doubles et les murs épais, (de sorte que) nulle clameur, nul brouhaha ne soit audible.

(27) Méthode pour préserver l'unité. Quand la clarté gagne les six externes ${ }^{144}$, la personne est alors sans dommage et l'on peut mener sa vie à son terme. Vous obtiendrez la pérennité.

(28) Préservez l'unité sans faute, toutes les choses s'accompliront et vous vous hâterez de rejeter tous les tourments. L'unité étant restaurée, vers quoi d'autre tendre?

140) La leçon du Taiping jing, HY 1093, 96.5b (WM, p. 410) donne "homme de peu" (xiaoren 小人) pour cette troisième catégorie humaine.

141) Une citation du Taiping jing dans le Taiping yulan (982), éd. Li Fang 李昉 (925-995), rééd. Beijing, Zhonghua shuju, 1960, 668.1a, définit "la voie de la nutrition du principe vital" comme "apaiser (sa) personne et nourrir le souffle, ne pas éprouver de joie ni de colère"; celui qui y parvient "est sans tourment et (obtient) ainsi de lui-même la longévité" 養生之道、安身養氣、不欲怒喜也、人無憂、故自壽也. Cette citation recoupe partiellement le Taiping jing chao, HY 1093, 10.9b (WM, p. 727): "Voie de la nutrition du principe vital. Apaiser la personne et nourrir le souffle, ne pas éprouver de joies ni de colères nombreuses. Les maîtres lucides de l'Antiquité enseignaient à tous les souverains comment apaiser (leur) personne pour faire en sorte qu'ils soient sans tourment, puis les souverains s'y consacraient d'eux-mêmes” 養生之道、安身養氣、不欲數怒喜也、古者 明師教帝王、皆安身使無憂、即帝王自專矣. La joie et la colère sont fréquemment critiquées dans le Huainan zi, par exemple comme obstacles à "l'incarnation de la Voie" (tidao 體道); voir A Concordance to the Huainanzi 淮南子逐字索引, éd. D. C. Lau, Hong Kong, The Commercial Press, 1992, 10/82/16.

142) La leçon du Taiping jing, HY 1093, 96.6a (WM, p. 410) précise que les "grands hommes", les "hommes moyens" et les "hommes de peu" - une hiérarchie ternaire répondant au verset 23 - préservent l'unité avec autant de profit: 夫守一者、大人守之亦有餘、中 人守之亦有餘、小人守之亦有餘.

143) Liufang bayuan 六方八遠, littéralement “les six secteurs et les huit lointains".

144) Liuwai 六外. L'expression désigne l'extérieur du corps dans les six directions de l'espace, selon Long (éd.), Taiping jing quanyi, p. 1537; Yang (éd.), Taiping jing jinzhu jinyi, p. 1767-1768. Dans le bouddhisme, la même expression désigne les six "qualités" produites par les objets au contact des organes des sens: vision, son, odeur, saveur, toucher et idée. 
(29) Préservez l'unité sans cesse. Officiers, vous qui aspirez à être sans tourment, vous ne pouvez pas vous tromper mutuellement et laisser pendre vos vêtements en joignant les mains ${ }^{145}$.

(30) Préserver l'unité, cela constitue une longue errance. Prendre constamment soin de soi-même et les malheurs seront éliminés.

(31) Méthode pour préserver l'unité. Les remèdes divins viennent d'euxmêmes ${ }^{146}$.

(32) Méthode pour préserver l'unité. Les calamités ordinaires ne font aucun dommage. Détenant chacun l'unité, les hommes n'ont pas besoin les uns des autres. Les tigres et les loups [4b] ne se montrent plus, les dragons ne s'élèvent plus, et toutes les créatures venimeuses vous évitent. Vous qui aspirez à être durablement sans tourment, recherchez l'unité, et les cent divinités et les mille mânes ne vous mettront plus en danger ${ }^{147}$. Consacrez-vous à préserver (l'unité) avec constance, et les désastres et les calamités ne reviendront plus.

(33) Méthode pour préserver l'unité. Ne pas parler en est la base. Fermer soigneusement sa porte ${ }^{148}$, préserver soigneusement ses divinités (corporelles) et ne pas oser (les) laisser échapper. L'extérieur étant obscur et l'intérieur lumineux, l'unité est alors réalisable.

(34) Méthode pour préserver l'unité. On voyagera avec les divinités, qui viendront d'elles-mêmes par myriades, radieuses, et qu'il sera possible d'accompagner.

(35) Quand on aspire à préserver l'unité, la joie et la colère sont des indispositions. L'unité est visible quand on n'est ni joyeux ni en colère.

145) Chui gong 垂拱, évocation de l'attitude paisible du souverain idéal dont le règne se caractérise par une concorde généralisée et ne nécessite aucune initiative politique. Sous les Tang, une ère du règne de Wu Zetian 武則天 (624-705) porta ce nom (685-688).

146) Shenyao zilai 神藥自來. Le Taiping jing chao, HY 1093, 6.3a (WM, p. 330) donne, dans un contexte similaire de méditation: "Les médications célestes descendent d'ellesmêmes”天醫自下.

147) Le thème remonte probablement au développement des expériences anachorétiques des premiers chercheurs d'immortalité. Dans le Baopu zi, Ge Hong reproduit et commente une vingtaine d'exemples d'écriture symbolique ( $f u$ 符) et de sceaux (yin 印) du Seigneur Lao 老君 que les taoïstes préparent afin d'“entrer dans les montagnes et les forêts” 入山林 sans craindre le danger représenté par diverses entités (démons et esprits de toutes sortes, tigres et loups, serpents et bêtes venimeuses, dragons, etc.). Toutes ces créatures s'écarteront de la route de l'utilisateur de ces talismans (Baopu zi neipian, HY 1177, 17.14a22b; voir Michel Strickmann, Chinese Magical Medicine, éd. Bernard Faure, Stanford, Stanford University Press, 2002, p. 141). Deux fois, Ge Hong prescrit d'associer à l'usage de ces talismans la pratique de "préservation de l'unité parfaite", shou zhenyi (12a, 13b), dont il a été question plus haut. On note que l'un des talismans présentés s'appelle "écriture symbolique de la Grande paix de Li Er”, Li Er taiping fu 李耳太平符 (21a); Li Er est le nom de Laozi dans la biographie que Sima Qian 司馬遷 (145-86 av. n. è.) lui consacre dans le Shiji 史記 (91 av. n. è.), rééd. Beijing, Zhonghua shuju, 1982, 63.2139.

148) Men 門, la porte de l'oratoire dans lequel l'adepte doit s'isoler, aussi bien, ici, que les points de communication du corps humain avec l'extérieur (yeux, oreilles, etc.). 
(36) Méthode pour préserver l'unité. À l'intérieur il y a les cinq protecteurs ${ }^{149}$, à l'extérieur les six observateurs ${ }^{150}$. Ces onze divinités sont du même ordre.

(37) Méthode pour préserver l'unité. Il importe de réfléchir à l'incorporéité originelle. La vie procède de l'union des fibres musculaires ${ }^{151}$ et des liquides corporels. [5a] En éliminant la vieillesse pour rajeunir, il est possible d'obtenir une vie longue. Si vous préservez l'unité, n'employez pas beaucoup de connaissances. Préservez l'unité sans relâche et il n'y a pas une seule chose que vous ne connaîtrez ${ }^{152}$. Vous obtiendrez tout ce que vous demandez et vous y parviendrez en étant assis bien droit. Vous qui aspirez à une grande joie, apprenez à connaître l'unité, renoncez aux honneurs et à la notoriété, alors vous serez en accord avec l'unité. Vous qui souhaitez profiter de vos vieux jours, préservez tôt l'unité. Assis ou allongé sur une couche plane, protégez l'unité et réciproquement ${ }^{153}$. Rassasiezvous sans vous alimenter et vous ne connaitrez ${ }^{154}$ pas le déclin de la vieillesse ${ }^{155}$.

(38) Méthode pour préserver l'unité. Tout progresse graduellement. Préservez-la longuement, premièrement jusqu'à atteindre cent jours.

(39) Méthode pour préserver l'unité. Ne vous laissez pas distraire, alors l'unité se manifestera d'elle-même.

(40) Quand on aspire à préserver l'unité, on entre alors en contact avec les divinités ${ }^{156}$. On cherche dans l'abdomen alors même que l'on est tranquillement allongé, sans interférer. On connaît l'est de la montagne alors même que l'on est allongé à l'ouest de la montagne.

(41) Méthode pour préserver l'unité. C'est la racine originelle des myriades de divinités. La racine étant profonde et les divinités sereines, il n’y a pas moyen de mourir. [5b]

149) Wushou 五守, les divinités des cinq organes qu’évoquent déjà les versets 17 et 18.

150) Liuhou 六候, les six divinités directrices du destin que mentionne le verset 49.

151) Cou 湊, ici synonyme de cou 腠, selon Yu (éd.), Taiping jing zhengdu, p. 562.

152) Cf. Baopu zi neipian, HY 1177, 18.1a: "Il n'y a pas une seule chose que ne connaisse celui qui connaît l'unite”” 知一者、無一之不知也. Voir Ware, Alchemy, Medicine, Religion, p. 301.

153) Cf. Jinque dijun sanyuan zhenyi jing, HY 253, 3b: “(Si) vous êtes capable de préserver l'unité, l'unité vous préserve aussi” 子能守一 、一亦守子. Cf. Andersen, The Method of Holding the Three Ones, p. 42: "If you can hold The Ones, The Ones will also hold you". Cette traduction est au pluriel car le Jinque dijun sanyuan zhenyi jing traite avant tout des trois unités (sanyi).

154) Lire de 得 pour de 德, selon Yu (éd.), Taiping jing zhengdu, p. 562 .

155) Leçon du Taiping yulan, 668.1a: "Vous qui souhaitez profiter de vos vieux jours, préserver l'unité (vous procure) la longévité la plus étendue. Apaisez (votre) souffle et allongezvous lentement, préservez l'unité et réciproquement. Quelle catastrophe personnelle (redouter quand) le souffle est semblable à une source? Cela constitue un trésor parfait. La sénilité s'élimine d'elle-même” 子欲養老、守一最壽、平氣徐臥、與一相守、氣若泉 源、其身何然、是爲真寶、衰老自去.

156) Cf. Baopu zi neipian, HY 1177, 18.2b: "Préserver l'unité et maintenir la perfection, et être alors capable d'entrer en contact avec les divinités” 守一存真、乃能通神. Voir Ware, Alchemy, Medicine, Religion, p. 303. 
(42) Méthode pour préserver l'unité. Vieux et jeunes (obéissent à) des règles différentes. C'est en fonction de ses dispositions naturelles que chacun rencontre l'unité.

(43) Méthode pour préserver l'unité. S'appauvrir tranquillement et prendre plaisir à l'humilité. C'est en cherchant constamment l'unité à l'intérieur de soi-même qu'on la verra ${ }^{157}$, et l'on comprendra qu'il n'y a ni noblesse ni humilité.

(44) Méthode pour préserver l'unité. S'alimenter peu en constitue la base. Les divinités parfaites aiment la propreté, la saleté des excréments trouble le souffle.

(45) Méthode pour préserver l'unité. Penser secrètement à ses points importants, complètement puis recommencer, sans fin ni limite. Le visage s'illumine et les divinités essentielles émettent une lueur pénétrante.

(46) Méthode pour préserver l'unité. Cent jours constituent une petite sérénité, deux cents jours une sérénité moyenne, trois cents jours une grande sérénité. À l'intérieur (cela) provoque un bonheur constant. Les trois cadavres ${ }^{158}$ sont déjà tombés.

(47) Méthode pour préserver l'unité. Il y a 366 (parties du corps) à énumérer ${ }^{159}$; à (chaque partie) énumérée correspond une essence, à (chaque) essence une divinité $^{160}$. L’œuvre de préserver l'unité étant accomplie, ces divinités deviennent visibles. [6a]

(48) Méthode pour préserver l'unité. Quand les cinq administrateurs internes ${ }^{161}$ errent du cour vers l'extérieur, alors l'intérieur n'est plus administré. On ne préserve pas bien l'unité, on va à contre-courant à l'intérieur en prenant soin de l'extérieur, suscitant le ressentiment de l'unité.

(49) Méthode pour préserver l'unité. En permanence, il y a les six directeurs du destin $^{162}$, divinités qui débattent ensemble des fautes des hommes.

157) Cf. Jinque dijun sanyuan zhenyi jing, HY 253, 1a: “la trinité peut être vue” 三一可見; 3b: “Vous qui êtes capable de voir l'unité, l'unité vous voit aussi” 子能見一、一亦見子. Voir Andersen, The Method of Holding the Three Ones, p. 39 et 42.

158) Sanshi三尺, agents parasitaires, également appelés sanchong 三蟲 (les “trois vers”), qui cherchent à hâter la mort de leur hôte pour s'émanciper, déjà mentionnés par Wang Chong 王充 (27-vers 100 de n. è.) et Ge Hong. Les taoïstes les évacuaient notamment en cessant d'absorber des céréales, dont se nourrissent ces parasites. Voir Jean Levi, "L'abstinence des céréales chez les taoïstes", Études chinoises 1 (1982): 3-47.

159) Shu 數. Dénombrer ( $s h u d u$ 數度) les parties constitutives du corps humain (verset 16) est le troisième des neuf principes énumérés précédemment.

160) Cf. manuscrit S.4226, col. 294: "Le second (juan de la) II (partie du Taipingjing) dit: (Le corps) humain (compte) 360 méridiens. (À chaque) méridien (correspond) une essence, (à chaque) essence (correspond) une divinité. Méditer sur les divinités jusqu'à devenir un homme de la Voie” 乙第二云、人三百六十脉、脉一精、精一神、思神至成道人 (Espesset, "Le manuscrit Stein 4226 Taiping bu juan di er dans l'histoire du taoïsme médiéval", p. 238).

161) Nei wuzheng 内五政, les divinités des cinq organes que mentionnent les versets 17, 18 et 36 .

162) Liu siming 六司命, les “six observateurs” (liuhou) que mentionne le verset 36. 
(50) Méthode pour préserver l'unité. C'est la base du contrôle de la bonté humaine par les divinités, la méthode pour écarter les malheurs et le moyen d'atteindre la félicité. Celui qui préserve l'unité contrôle l'instrument divin. Procédant par accumulation, d'une divinité jusqu'à en atteindre des myriades, il obtiendra la Voie avec le même instrument unique.

(51) Méthode pour préserver l'unité. Si, à l'intérieur, on va à contre-courant de la norme, les cinq viscères ${ }^{163}$ sont désorganisés et les six entrailles ${ }^{164}$ ne sont plus préservées. La multitude des divinités s'effraie et s'afflige, toutes sortent (du corps) et font leur rapport au Palais de la clarté165. Cela se manifeste d'abord immanquablement par le teint du visage. Ensemble, le ciel et la terre le savent. Quand la multitude des divinités s'en sera allée, le corps mourra.

(52) Méthode pour préserver l'unité. Faire preuve de bonté et le résultat sera visible. (Quand) on fait ${ }^{166}$ (chaque) jour se manifester la bonté, la pureté et la quiétude, les divinités [6b] émettent progressivement une clarté, au début comme celle des lucioles, à la longue comparable à l'éclat de la foudre.

(53) Méthode pour préserver l'unité. À l'extérieur, acquérir du mérite en se conduisant avec humanité et en répandant les bienfaits, sans en attendre de rétribution. Même chose pour la droiture et la dévotion filiale.

(54) Méthode pour préserver l'unité. Il y a cent sortes de félicité mais aussi cent malheurs. (Quand) on préserve (l'unité mais) sans s'y consacrer entièrement, (quand) les raisons de s'affairer à l'extérieur sont nombreuses, les cent divinités entrent en conflit, succès et revers se succèdent.

(55) Méthode pour préserver l'unité. (Celui qui), à l'intérieur, s'y consacre constamment, les divinités l'aiment comme un nouveau-né. Comment les cent malheurs oseraient-ils l'affliger?

(56) Méthode pour préserver l'unité. À l'égal des divinités du ciel et de la terre, sortir du Yin et entrer dans le Yang ${ }^{167}$. Il n'y a nulle affaire que l'on ne pénètre. 163) Wugong 五宮, les “cinq palais”, équivalent de wuzang 五臟 dans la physiologie taoïste.
${ }^{164)}$ Liufu 六府, variante graphique de liufu 六腑.
${ }^{165)}$ Mingtang. Originellement, il s'agit de l'espace politique et symbolique parcouru par l'empereur en fonction des saisons et qui admet des correspondances notamment astronomiques et physiologiques. Dans les strates textuelles minoritaires du Taiping jing, HY 1093, 111.1a, 112.5b-8a, 114.29a et 114.40b (WM, p. 544, 568, 614-615 et 624), l'expression désigne l'organe central de l'administration céleste, dirigé par une divinité majeure (dashen 大神) et chargé principalement de la gestion des rapports soumis par les divinités qui assurent au quotidien la surveillance de la conduite humaine; voir Espesset, "Criminalized Abnormality, Moral Etiology, and Redemptive Suffering in the Secondary Strata of the Taiping jing", p. 11-12.

160) Lire ling 令 pour jin 今, selon Yu (éd.), Taiping jing zhengdu, p. 563.

167) C'est-à-dire quitter le monde de la mort pour entrer dans celui de la vie. Selon le Taiping jing chao, HY 1093, 9.19b (WM, p. 716), "le Yang préserve l'unité et le Yin préserve la dualité”陽者守一、陰者守二. Dans tout ce passage, shouyi a le sens de “préserver l'unité de la personne" 守一身, faisant écho au Taiping jing, HY 1093, 112.4b (WM, p. 566), qui parle de "préserver l'unité du corps" 守一身軀. Le Taiping jing, HY 1093, 103.2a (WM, 
(57) Méthode pour préserver l'unité. D’abord connaitre les desseins du ciel, qui engendre et transforme les dix mille êtres, gouverne sans parler, et œuvre [7a] sans exercer d'autorité. La Voie engendre la vision pérenne (ou perpétuité) ${ }^{168}$.

(58) Méthode pour préserver l'unité. On peut connaître des myriades de choses, mais ces myriades de choses ne permettent pas de connaitre l'unité. Celui qui préserve l'unité peut transcender la durée de la vie humaine, dissiper les désastres, servir son souverain, ne pas mourir, gouverner sa famille, servir les divinités, ne pas connaître la détresse, soigner les maladies, connaître la longévité et la perpétuité. (L'unité) est le principe du souffle primordial, la cheville ouvrière des dix mille êtres. (S')ils ne préservaient pas l'unité, le ciel perdrait sa pureté, la terre perdrait sa tranquillité, le soleil perdrait sa luminosité, la lune perdrait sa brillance ${ }^{169}$, les astres s'écarteraient de leur trajectoire, les montagnes ne pourraient éviter de s'écrouler, les cours d'eau s'assécheraient, les divinités n'engendreraient ni ne réaliseraient rien, et les hommes ne vivraient pas $^{170}$. L'unité est l'origine dont procèdent toutes les choses. Connaissez l'unité et vous accomplirez des myriades de choses. [7b]

Directives secrètes $^{171}$ du Saint Seigneur du Livre de la Grande paix.

\section{Bibliographie}

Andersen, Poul. The Method of Holding the Three Ones: A Taoist Manual of Meditation of the Fourth Century A.D., Londres, Curzon Press, 1979

Ban Gu 班固. Han shu 漢書, rééd. Beijing, Zhonghua shuju, 1962

Baxter, William H. A Handbook of Old Chinese Phonology, Berlin, Mouton de Gruyter, 1992

Bokenkamp, Stephen R. "Traces of Early Celestial Master Physiological Practice in the Xiang'er Commentary”, Taoist Resources 4, 2 (1993): 37-51

p. 470) affirme aussi, dans un passage en grande partie tétrasyllabique et rimé, que "préserver la dualité et oublier l'unité, c'est perdre la racine” 守二忘一、失其相 (=根) 也. Ma correction est confirmée par les rimes auxquelles obéit le passage (gen 根 rime avec shen 神 et men 門).

168) 道生久視, phrase peut-être construite sur le modèle de la célèbre expression 長生久視 du Laozi, chapitre 59, abondamment reprise dans la littérature postérieure et que l'on retrouve, scindée en deux parties, dans le dernier verset ( $\left.n^{\circ} 58\right)$ de notre recueil: 可以長生、 可以久視 $(7 a)$.

169) Jing 精. Sur le caractère polysémique de ce mot, voir la n. 113 ci-dessus.

170) La pureté (qing 清) du ciel, la tranquillité (ning 寧) de la terre, la vitalité (sheng生) de l'homme et la nature surnaturelle (ling 靈) des divinités sont autant de qualités qui procèdent toutes de l'unité, selon le Baopu zi neipian, HY 1177, 18.1a; voir Ware, Alchemy, Medicine, Religion, p. 301. Le passage dérive bien entendu du chapitre 39 du Laozi.

171) $M i$ 祕 est orthographié 秘 dans le titre final, sans altération de sens. 
—. "Time After Time: Taoist Apocalyptic History and the Founding of the T'ang Dynasty", Asia Major, 3 e série, 7 (1994): 59-88

—. Early Daoist Scriptures, with a contribution by Peter Nickerson, Berkeley, University of California Press, 1997

Boltz, Judith Magee. "Notes on modern editions of the Taoist Canon", Bulletin of the School of Oriental and African Studies 56, 1 (1993): 87-95

Cedzich, Ursula-Angelika. "Das Ritual der Himmelsmeister im Spiegel früher Quellen: Übersetzung und Untersuchung des liturgischen Materials im dritten Chüan des Teng-chen yin-chüeh", thèse de la Julius-Maximilians-Universität, Würzburg, 1987

Chen Shou 陳壽. Sanguo zhi 三國志, rééd. Beijing, Zhonghua shuju, 1959

Chuandeng 傳燈. Tiantai shan fangwai zhi 天台山方外志, in Dazang jing bubian 大 藏經補編, Taipei, Huayu chubanshe, 1984-1986, vol. 30

de Crespigny, Rafe. Portents of Protest in the Later Han Dynasty: The Memorials of Hsiang K'ai to Emperor Huan, Canberra, Faculty of Asian Studies in association with Australian National University Press, 1976

- A Biographical Dictionary of Later Han to the Three Kingdoms (23-220 AD), Leiden et Boston, E. J. Brill, 2007

Csikszentmihảlyi, Mark. "Ethics and their relationship to self-cultivation practice", in Early Chinese Religion. Part One: Shang through Han (1250 BC-220 AD), éd. John Lagerwey et Marc Kalinowski, Leiden, E. J. Brill, 2009, p. 543-594

Daode zhenjing zhu 道德真經註, attribué à Heshang gong 河上公, HY 682

Dongzhen taishang suling dongyuan dayou miaojing 洞真太上素靈洞元大有妙經, HY 1303

Du Guangting 杜光庭 (éd.). Daode zhenjing guangsheng yi 道德真經廣聖義, HY 725

Durkheim, Émile. L'individualisme et les intellectuels, 1898, rééd. Paris, Mille et une nuits, 2002

Eichhorn, Werner. “T'ai-p'ing und T'ai-p'ing-Religion”, Mitteilungen des Instituts für Orientforschung 5, 1 (1957): 113-140

Erkes, Eduard. Ho-shang-kung's Commentary on Lao-tse, Ascona, Artibus Asiae, 1950 Espesset, Grégoire. "Cosmologie et trifonctionnalité dans l'idéologie du Livre de la Grande paix (Taiping jing 太本經)”, thèse de l'Université Paris VII, Paris, 2002 . "Criminalized Abnormality, Moral Etiology, and Redemptive Suffering in the Secondary Strata of the Taiping jing", Asia Major, $3^{\mathrm{e}}$ série, 15, 2 (2002): 1-50 - "À vau-l'eau, à rebours ou l'ambivalence de la logique triadique dans l'idéologie du Taiping jing 太本經”, Cahiers d'Extrême-Asie 14 (2004): 61-95

. “Le manuscrit Stein 4226 Taiping bu juan di er 太本部卷第二 dans l'histoire du taoïsme médiéval", in Études de Dunhuang et Turfan, textes réunis par JeanPierre Drège avec la collaboration d'Olivier Venture, Genève, Droz, 2007, p. $189-256$

. "Editing and Translating the Taiping Jing and the Great Peace Textual Corpus", Zhongguo wenhua yanjiusuo xuebao 48 (2008): 469-486 
—. "Latter Han religious mass movements and the early Daoist church", in Early Chinese Religion. Part One: Shang through Han (1250 BC-220 AD), éd. John Lagerwey et Marc Kalinowski, Leiden, E. J. Brill, 2009, p. 1061-1102

Fan Ye 范瞱. Hou Han shu 後漢書, rééd. Beijing, Zhonghua shuju, 1965

Fukui Kōjun 福井康順. Dōkyō no kisoteki kenkyü 道教の基礎的研究, $2^{\mathrm{e}}$ éd., Tōkyō,

Shoseki bunbutsu ryūtsūkai, 1958

Ge Hong 葛洪. Baopu zi neipian 抱朴子內篇, HY 1177

Giles, Lionel. Descriptive Catalogue of the Chinese Manuscripts from Tunhuang in the British Museum, Londres, The Trustees of the British Museum, 1957

Graham, Angus C. Chuang-Tzǔ: The Seven Inner Chapters and Other Writings from the Book Chuang-tzu, Londres, George Allen \& Unwin, 1981

Graziani, Romain. "The subject and the sovereign: exploring the self in early Chinese self-cultivation", in Early Chinese Religion. Part One: Shang through Han (1250 $B C-220 A D)$, éd. John Lagerwey et Marc Kalinowski, Leiden, E. J. Brill, 2009, p. $459-517$

Harper, Donald J. Early Chinese Medical Literature: The Mawangdui Medical Manuscripts, Londres et New York, Kegan Paul International, 1998

Hendrischke, Barbara. "The Concept of Inherited Evil in the Taiping Jing", East Asian History 2 (1991): 1-30

(trad.). The Scripture on Great Peace: The Taiping jing and the Beginnings of Daoism, Berkeley, University of California Press, 2006

Huangdi taiyi bamen nishun shengsi jue 黃帝太一八門逆順生死訣, HY 588

Huangtian Shangqing jinque dijun lingshu ziwen shangjing 皇天上清金閶帝君靈書紫 文上經, HY 639

Hucker, Charles O. A Dictionary of Official Titles in Imperial China, Stanford, Stanford University Press, 1985

Jia Shanxiang 賈善翔. Youlong zhuan 唒龍傳, HY 773

Jinque dijun sanyuan zhenyi jing 金関帝君三元真一經, HY 253

Kaltenmark, Max. Le Lie-sien tchouan: Biographies légendaires des Immortels taoïstes de l'antiquité, $2^{\mathrm{e}}$ éd., Paris, Collège de France, Institut des hautes études chinoises, 1987 (éd. originale 1953)

Kameda Masami 龜田勝見. “Jōsei kōsei dōkun rekki ni okeru shumin shisō ni tsuite: Taiheikyō-shō kōbu to no kankei o majiete” 上清後聖道君列紀における種民思 想について 太平經鈔甲部との關係を交えて, Nippon Chügoku gakkaihō 50 (1998): 77-91

Kamitsuka Yoshiko 神塚淑子. Rikuchō dōkyō shisō no kenkyū 六朝道教思想の研究， Tōkyō, Sōbunsha, 1999

Kandel, Barbara. Taiping jing. The Origin and Transmission of the "Scripture on General Welfare": The History of an Unofficial Text, Hamburg, Gesellschaft für Natur- und Völkerkunde Ostasiens, 1979

Kobayashi Masayoshi 小林正美. Rikuchō dōkyō-shi kenkyū 六朝道教史研究, Tōkyō,

Sōbunsha, 1990

Kohn, Livia. "Guarding the One: Concentrative Meditation in Taoism", in Taoist Meditation and Longevity Techniques, éd. Livia Kohn et Sakade Yoshinobu 坂出祥 信, Ann Arbor, The University of Michigan Press, 1989, p. 125-158 
(trad.). The Taoist Experience: An Anthology, New York, State University of New York Press, 1993

Kroll, Paul W. "Body Gods and Inner Vision: The Scripture of the Yellow Court", in Religions of China in Practice, éd. Donald S. Lopez, Jr., Princeton, Princeton University Press, 1996, p. 149-155

[Laozi daojing, shang, Xiang'er 老子道經上想爾], Londres, British Library, manuscrit Stein 6825 (Or.8210/S.6825/R.1)

Lau, D. C. (éd.). A Concordance to the Huainanzi 淮南子逐字索引, Hong Kong, The Commercial Press, 1992

(éd.). A Concordance to the Laozi 老子逐字索引, Hong Kong, The Commercial Press, 1996

(éd.). A Concordance to the Zhuangzi 莊子逐字索引, Hong Kong, The Commercial Press, 2000

Levi, Jean. "L’abstinence des céréales chez les taoïstes", Études chinoises 1 (1982): 3-47

Li Fang 李昉 (éd.). Taiping yulan 太本御覽, rééd. Beijing, Zhonghua shuju, 1960

Li Gang 李剛. "Ye lun Taiping jing chao jia bu ji qi yu daojiao Shangqing pai zhi guanxi” 也論太本經鈔甲部及其與道教上清派之關係, Daojia wenhua yanjiu 4 (1994): 284-299

Li Yue 李約 (éd.). Daode zhenjing xinzhu 道德真經新註, HY 692

Liangqiu zi 梁丘子 (Bo Lüzhong 白履忠). Huangting neijing yujing zhu 黃庭内景玉 經註, HY 402

Liexian zhuan 列仙傳, traditionnellement attribué à Liu Xiang 劉向, HY 294

Liu Xiaogan. "Naturalness (Tzu-jan), the Core Value in Taoism: Its Ancient Meaning and its Significance Today", in Lao-tzu and the Tao-te-ching, éd. Livia Kohn et Michael LaFargue, Albany, State University of New York Press, 1998, p. $211-228$

Long Hui 龍晦 (éd.). Taiping jing quanyi 太平經全譯, Guiyang, Guizhou renmin chubanshe, 2000

Luo Changpei 羅常培 et Zhou Zumo 周祖謨. Han Wei Jin Nanbei chao yunbu yanbian yanjiu 漢魏晉南北朝韻部演變研究, vol. 1, Beijing, Kexue chubanshe, 1958

Luo Chi 羅熾 (éd.). Taiping jing zhuyi 太本經注譯, Chongqing, Xinan shifan daxue, 1996

Lüqiu Fangyuan 閭丘方遠. Taishang dongxuan lingbao dagang chao 太上洞玄靈寶大 綱鈔, HY 393

—— (éd.). Dongxuan lingbao zhenling weiye tu 洞玄靈寶真靈位業圖, HY 167

Lynn, Richard John (trad.). The Classic of the Way and Virtue. A New Translation of the Tao-te Ching of Laozi as Interpreted by Wang Bi, New York, Columbia University Press, 1999

Maeda Shigeki 前田繁樹. Shoki dōkyō kyōten no keisei 初期道教經典の形成, Tōkyō, Kyūko shoin, 2004

Mansvelt Beck, Burchard J. "The Date of the Taiping Jing", T'oung Pao 66, 4-5 (1980): 149-182

Maspero, Henri. Le Taoïsme et les religions chinoises, Paris, Gallimard, 1971 
Meng Anpai 孟安排. Daojiao yishu 道教義樞, HY 1121

Mollier, Christine. Une apocalypse taoïste du Ve siècle: Le Livre des Incantations Divines des Grottes Abyssales, Paris, Collège de France, Institut des hautes études chinoises, 1990

Mugitani Kunio 麥谷邦夫. “Kōtei naikei-kyō shiron” 黄庭内景經試論, Tōyō bunka 62 (1982): 29-61

—. “Daidō shinkyō sanjūkyū-shō o megutte” 大洞真經三十九章おめぐつて, in Chügoku ko dōkyō shi kenkyū 中国古道教史研究, éd. Yoshikawa Tadao 吉川忠夫, Kyōto, Dōhōsha, 1992, p. 55-87

Needham, Joseph. The Grand Titration: Science and Society in East and West, Londres, George Allen \& Unwin, 1969

Ōfuchi Ninji 大淵忍爾. Tonkō dōkyō: zuroku-hen 敦煌道經——圖錄編, Tōkyō, Fukutake shoten, 1979

Oyanagi Shigeta 小柳司気太, “Go Kan jo Jō Kai den no Taihei shōryō-sho ni tsuite” 後漢書襄楷傳の太本清領書について, in Töyō-shi ronsō 東洋史論叢, éd. Kuwabara hakushi kanreki kinen kai 桑原博士還暦記念会, Kyōto, Kōbundō, 1930, p. $141-171$

Petersen, Jens Østergård. "The Early Traditions Relating to the Han Dynasty Transmission of the Taiping jing", Acta Orientalia (Copenhague) 50 (1989): 133-171; 51 (1990): 173-216

Pregadio, Fabrizio et Lowell Skar. "Inner Alchemy (Neidan)", in Daoism Handbook, éd. Livia Kohn, Leiden, E. J. Brill, 2000, p. 464-497

Rao Zongyi 饒宗頤. Laozi Xiang'er zhu jiaojian 老子想爾注校茂, Hong Kong, Tong Nam Printers \& Publishers, 1956

Raz, Gil. "Creation of Tradition: The Five Talismans of the Numinous Treasure and the Formation of Early Daoism", thèse de l'Indiana University, Bloomington, 2004

. "Time Manipulation in Early Daoist Ritual: The East Well Chart and the Eight Archivists", Asia Major, 3e série, 18, 2 (2005): 27-65

Ren Jiyu 任繼愈 et Zhong Zhaopeng 鍾肇鵬 (éd.). Daozang tiyao 道藏提要, $3^{\mathrm{e}}$ éd., Beijing, Zhongguo shehui kexue chubanshe, 2005

Robinet, Isabelle. Méditation taö̈ste, Paris, Dervy, 1979

. "Le Ta-tung chen-ching: Son authenticité et sa place dans les textes du Shangch'ing ching", in Tantric and Taoist Studies in Honour of Rolf A. Stein, vol. 2, éd. Michel Strickmann, Bruxelles, Institut belge des hautes études chinoises, 1983, p. 394-433

—. La révélation du Shangqing dans l'histoire du taoüsme, Paris, École française d'Extrême-Orient, 1984, 2 vol.

. "Notes préliminaires sur quelques antinomies fondamentales entre le Bouddhisme et le Taoïsme", in Incontro di religioni in Asia tra il III ed il X secolo d.C., éd. Lionello Lanciotti, Florence, Leo S. Olschki, 1984, p. 217-242 “Jing, qi et shen", Revue Française d'Acupuncture 43 (1985): 27-36 
. "Nature et rôle du maître spirituel dans le taoïsme non liturgique", in Maître et disciples dans les traditions religieuses, éd. Michel Meslin, Paris, Cerf, 1990, p. $37-50$

—. "De quelques effets du bouddhisme sur la problématique taoïste: Aspects de la confrontation du taoïsme au bouddhisme", in Religion and Chinese Society, vol. 1, Ancient and Medieval China, éd. John Lagerwey, Hong Kong, The Chinese University, École française d'Extrême-Orient, 2004, p. 411-516

Sakade Yoshinobu 坂出祥信. Dōkyō to yōjō shisōi道教と養生思想, Tōkyō, Perikan-sha, 1992

Schipper, Kristofer. "Millénarismes et messianismes dans la Chine ancienne", in Understanding Modern China. Problems and Methods, éd. Lionello Lanciotti et Piero Corradini, Roma, Centro Ricerche Sinologiche, Istituto Italiano per il Medio ed Estremo Oriente, 1979, p. 31-49

- Le corps taoïste: Corps physique, corps social, Paris, Fayard, 1982

- La religion de la Chine: La tradition vivante, Paris, Fayard, 2008

- (éd.). Concordance du Houang-t'ing king: Nei-king et Wai-king, Paris, École française d'Extrême-Orient, 1975

Schipper, Kristofer et Franciscus Verellen (éd.). The Taoist Canon: A Historical Companion to the Daozang, Chicago, The University of Chicago Press, 2004

Seidel, Anna. "The Image of the Perfect Ruler in Early Taoist Messianism: Lao-tzu and

Li Hung", History of Religions 9, 2-3 (1969-1970): 216-247

. “Taoist Messianism”, Numen 31 (1983): 161-174

Shangqing housheng daojun lieji 上清後聖道君列紀, HY 442

Shen Fen 沈汾 (éd.). Xuxian zhuan 續仙傳, HY 295

Sima Qian 司馬遷. Shiji 史記, rééd. Beijing, Zhonghua shuju, 1982

Stein, Rolf A. "Aspects de la foi jurée en Chine", Annuaire du Collège de France 67" année (1967): 411-415

—. "Textes taoïstes relatifs à la transmission des livres révélés", Annuaire du Collège de France $68^{\mathrm{e}}$ année (1968): 453-457

Strickmann, Michel. Chinese Magical Medicine, éd. Bernard Faure, Stanford, Stanford University Press, 2002

Su Baoyang 蘇抱陽. “Taiping jing chengshu de jige wenti” 太平經成書的幾個問題, Shijie zongjiao yanjiu 50, 4 (1992): 14-21

[Taiping bu juan di er 太平部卷第二], Londres, British Library, manuscrit Stein 4226 (Or.8210/S.4226/R.1)

Taiping jing 太本經, HY 1093, juan 35-119

Taiping jing 太平經. Shanghai, Shanghai guji chubanshe, “Zhuzi baijia congshu” 諸 子百家叢書, 1993

Taiping jing chao 太本經鈔, HY 1093, juan 1-10

Taiping jing fuwen xu 太平經複文序, HY 1093, Préface Taiping jing shengjun mizhi 太平經聖君祕旨, HY 1094

Taishang huangting neijing yujing 太上黃庭内景玉經, HY 331

Taishang huangting waijing yujing 太上黃庭外景玉經, HY 332

Taishang Lao jun zhongjing 太上老君中經, HY 1160 
Taishang lingbao wufu xu 太上靈寶五符序, HY 388

Tang Yijie 湯一介. “Guanyu Taiping jing chengshu wenti” 關於太本經成書問題, Zhongguo wenhua yanjiu jikan 1 (1984): 168-186

Tang Yongtong 湯用粀. “Du Taiping jing shu suo jian” 讀太平經書所見, Guoxue jikan 5, 1 (1935): 7-38

Tao Hongjing 陶弘景 (éd.). Dengzhen yinjue 登真隱訣, HY 421

Tuotuo 脫脫 (éd.). Song shi 宋史, rééd. Beijing, Zhonghua shuju, 1977

Wang Bi 王腼 (éd.). Daode zhenjing zhu 道德真經詿, HY 690

Wang Juncai 王俊才 (éd.). “Taipingjing shengjun mizhi”太本經聖君班旨, in Wenbai duizhao daojiao shisan jing 文白對照道教十三經, éd. Ning Zhixin 寧志新, Shijiazhuang, Hebei renmin chubanshe, 1994, p. 1010-1020

Wang Ka 王卡 (éd.). “005 - Taipingjing shengjun mizhi” 太本經聖君祕旨, in Zhonghua daozang 中華道藏, éd. Zhang Jiyu 張繼禹, Beijing, Huaxia chubanshe, 2004, vol. 7, p. 318-320

Wang Ming 王明. “Lun Taiping jing chao jia bu zhi wei” 論太本經鈔甲部之䋒, Lishi yuyan yanjiusuo jikan 18 (1948): 375-384

(éd.). Taiping jing hejiao 太平經合校, $2^{\mathrm{e}}$ éd., Beijing, Zhonghua shuju, 1979

Ware, James R. (trad.). Alchemy, Medicine, Religion in the China of A.D. 320: The Nei P'ien of Ko Hung (Pao-p'u tzu), Cambridge (Mass.), Massachusetts Institute of Technology, 1966

Weng Dujian 翁獨薦 (éd.). Daozang zimu yinde 道藏子目引得, Harvard-Yenching Institute Sinological Index Series $n^{\circ} 25$, Beijing, Yenching University Library, 1935

Wieger, Léon. Taoïsme. Tome I: Bibliographie générale, Hien-hien, Imprimerie de la Mission, 1911

Xiuzhen shishu 修真十書, HY 263

Xun Yue 荀悅. Han ji 漢紀, rééd. Beijing, Zhonghua shuju, 2002

Yamada Toshiaki [山田利明. Rikuchō dókyō girei no kenkyū 六朝道教儀禮の研究,

Tōkyō, Tōhō shoten, 1999

Yang Jilin 楊寄林 (éd.). “Taipingjing shidu” 太本經釋讀, in Zhonghua daoxue tongdian 中華道學通典, éd. Wu Feng 吳楓 et Song Yifu 宋一夫, Haikou, Nanhai chuban gongsi, 1994, p. 267-656

(éd.). Taiping jing jinzhu jinyi 太本經今注今譯, Shijiazhuang, Hebei renmin chubanshe, 2002

Yoshioka Yoshitoyo 吉岡義豐. Dōkyō to Bukkyō 道教と仏教, vol. 3, Tōkyō, Kokusho kankōkai, 1976

Yu Liming 命理明 (éd.). Taipingjing zhengdu 太平經正讀, Chengdu, Ba Shu shushe, 2001

Yuan Miaozong 元妙宗. Taishang zhuguo jiumin zongzhen miyao 太上助國救民總真 祕要, HY 1217

Zhang Guangbao 張廣保. “Taiping jing: neidan dao de chengli” 太本經一一內丹道 的成立, Daojia wenhua yanjiu 16 (1999): 123-150

Zhang Junfang 張君房 (éd.). Yunji qiqian 雲笈七籤, HY 1026

Zhang Tianyu 張天雨 (éd.). Xuanpin lu 玄品錄, HY 780 
Zhao Daoyi 趙道一 (éd.). Lishi zhenxian tidao tongjian 歷世真仙體道通鑑, HY 296 Zhengyi fawen taishang wailu yi 正一法文太上外籙儀, HY 1233

Zhengyi fawen tianshi jiaojie kejing 正一法文天師教戒科經, HY 788

Zhou Zumo 周祖謨. Zhou Zumo yuyan wenshi lunji 周祖謨語言文史論集, Hangzhou, Zhejiang guji chubanshe, 1988

Zürcher, Erik. The Buddhist Conquest of China: The Spread and Adaptation of Buddhism in Early China, Leiden, E. J. Brill, 1959

. "Buddhist Influence on Early Taoism: A Survey of Scriptural Evidence", T'oung Pao 66, 1-3 (1980): 84-147 